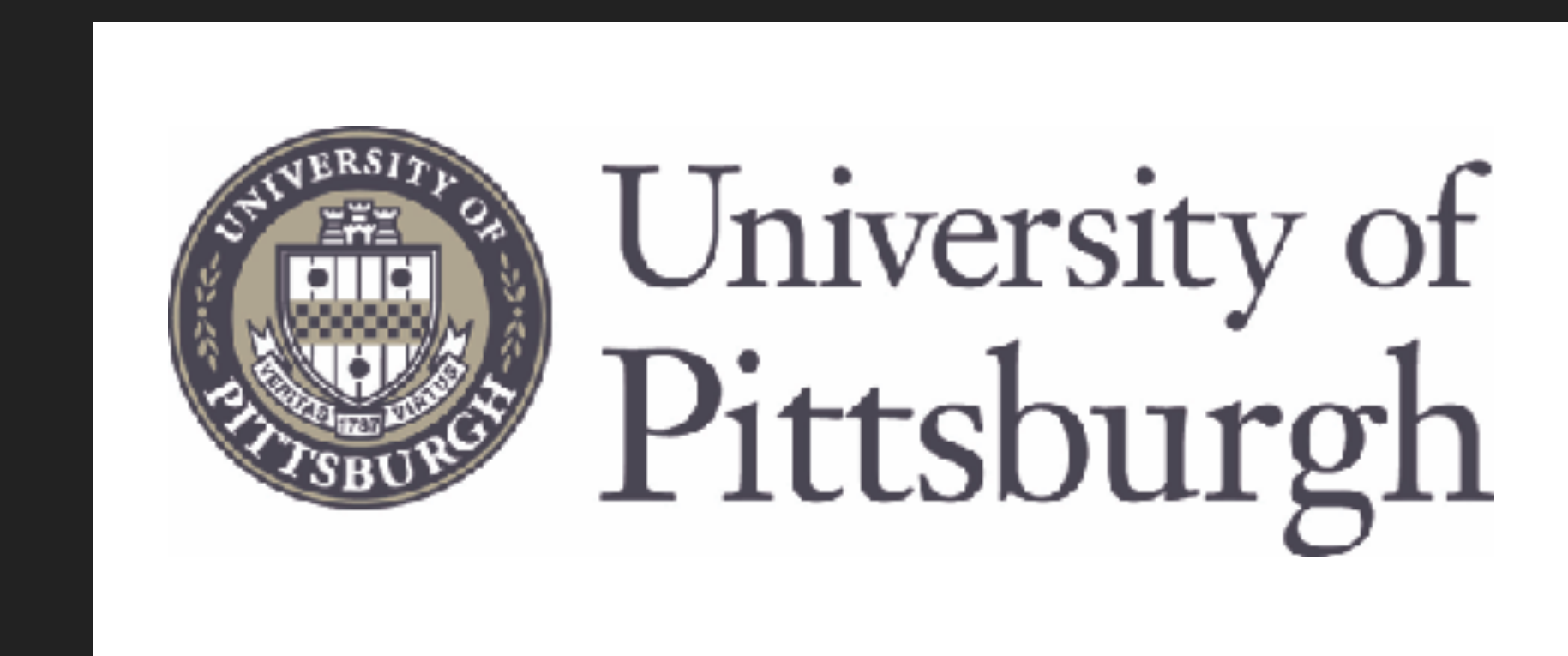

University of Pittsburgh Department of Geology and Environmental Science

\author{
Júlio Caineta and Brian F. Thomas
}

\title{
EXPLORING LINKS BETWEEN SEA SURFACE TEMPERATURE AND COLOR IN COASTAL AREAS UNDER THE EFFECT OF SUBMARINE GROUNDWATER DISCHARGE
}




\section{SUBMARINE GROUNDWATER DISCHARGE}
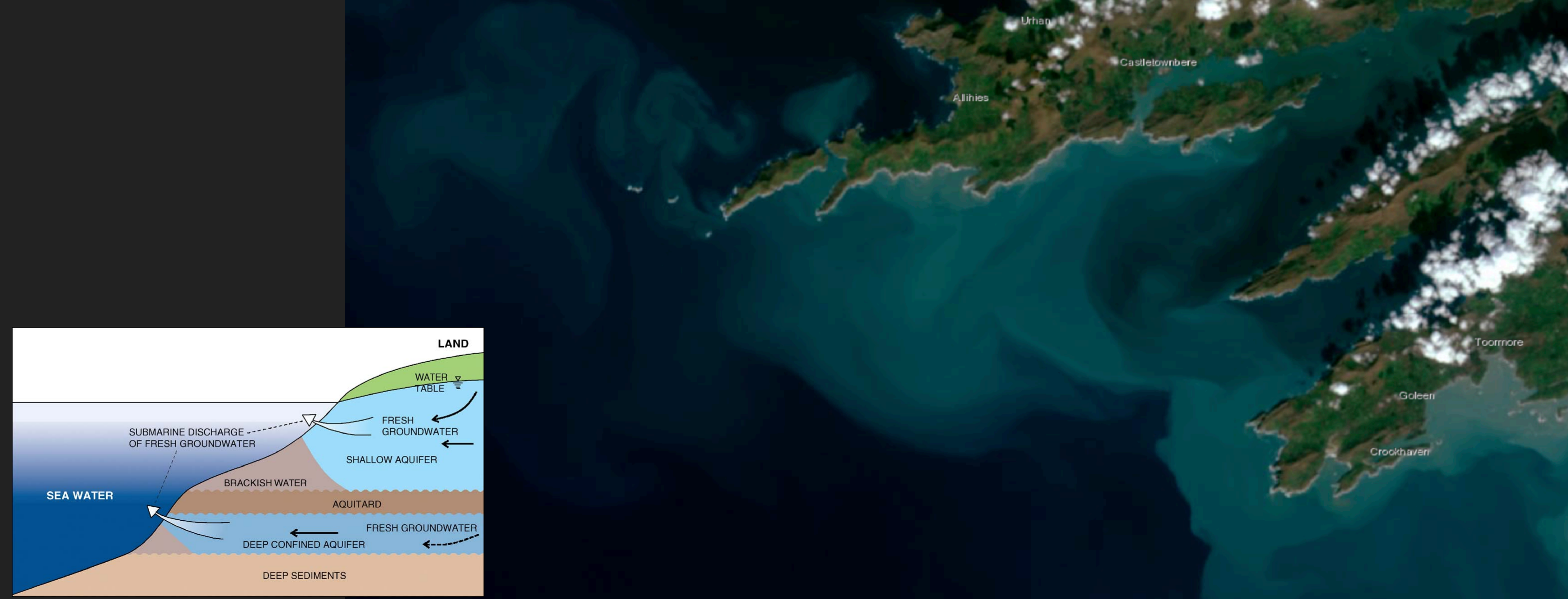


\section{MOTIVATION}

\section{SUBMARINE GROUNDWATER DISCHARGE}

D Remote sensing approaches use TIR

- Move to field measurements to further assess SGD

- Can we go further with remote sensing data?

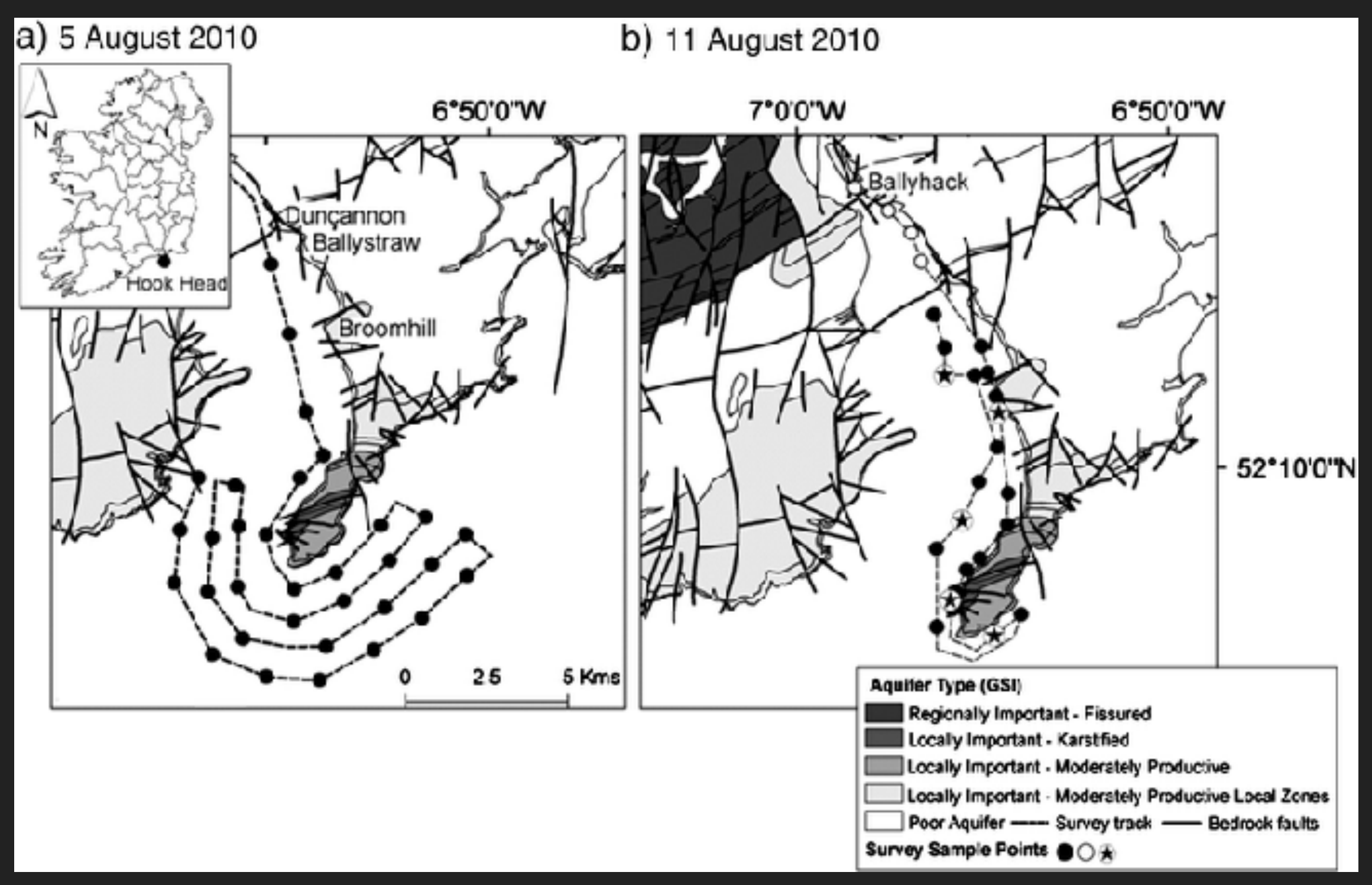

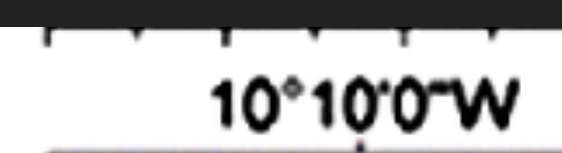

$9^{\circ} 30^{\circ} 0 \mathrm{~W}$ d)
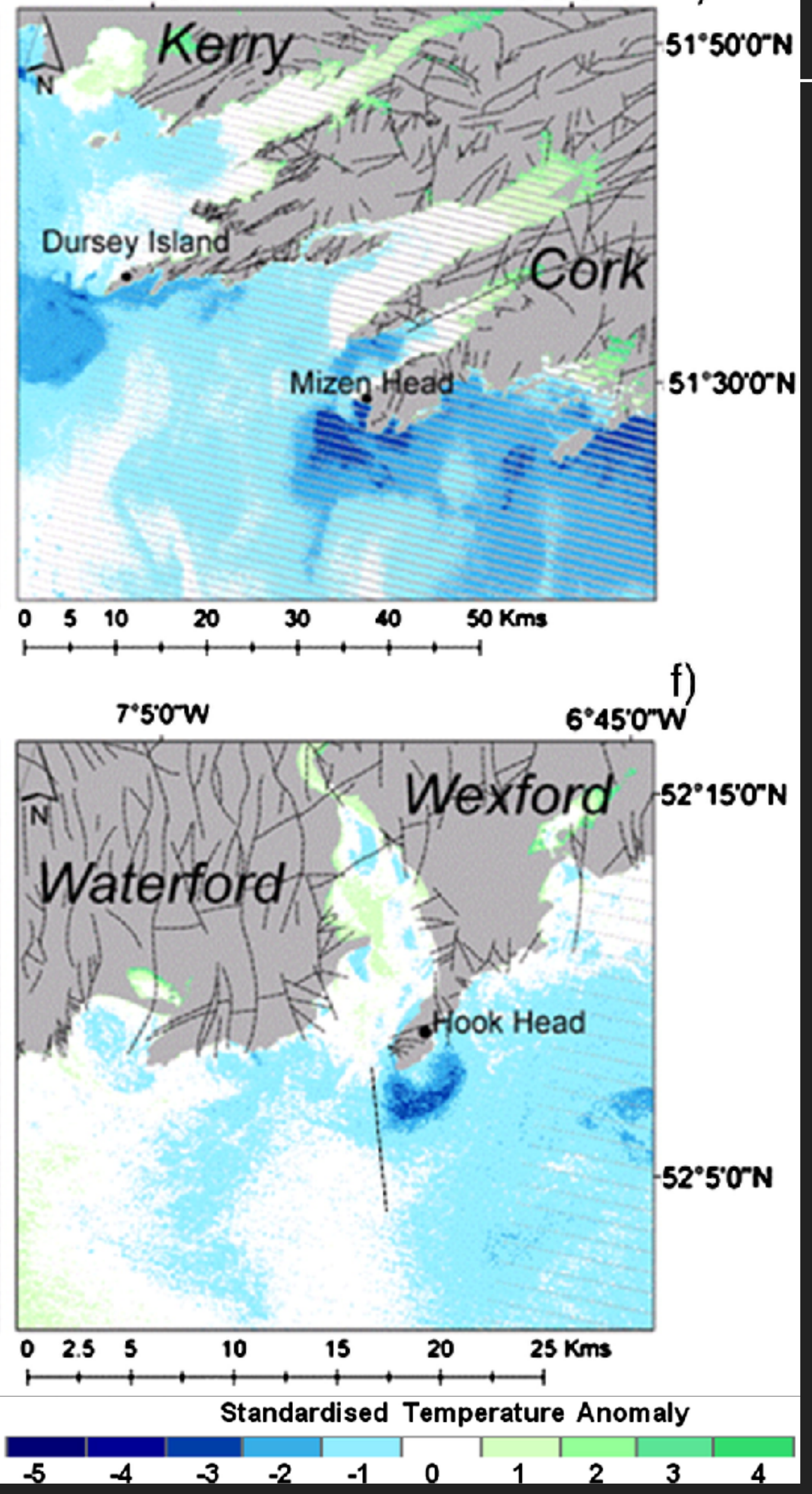


\section{IN THIS STUDY}

- links to SST

links to color

v TIR and VIS

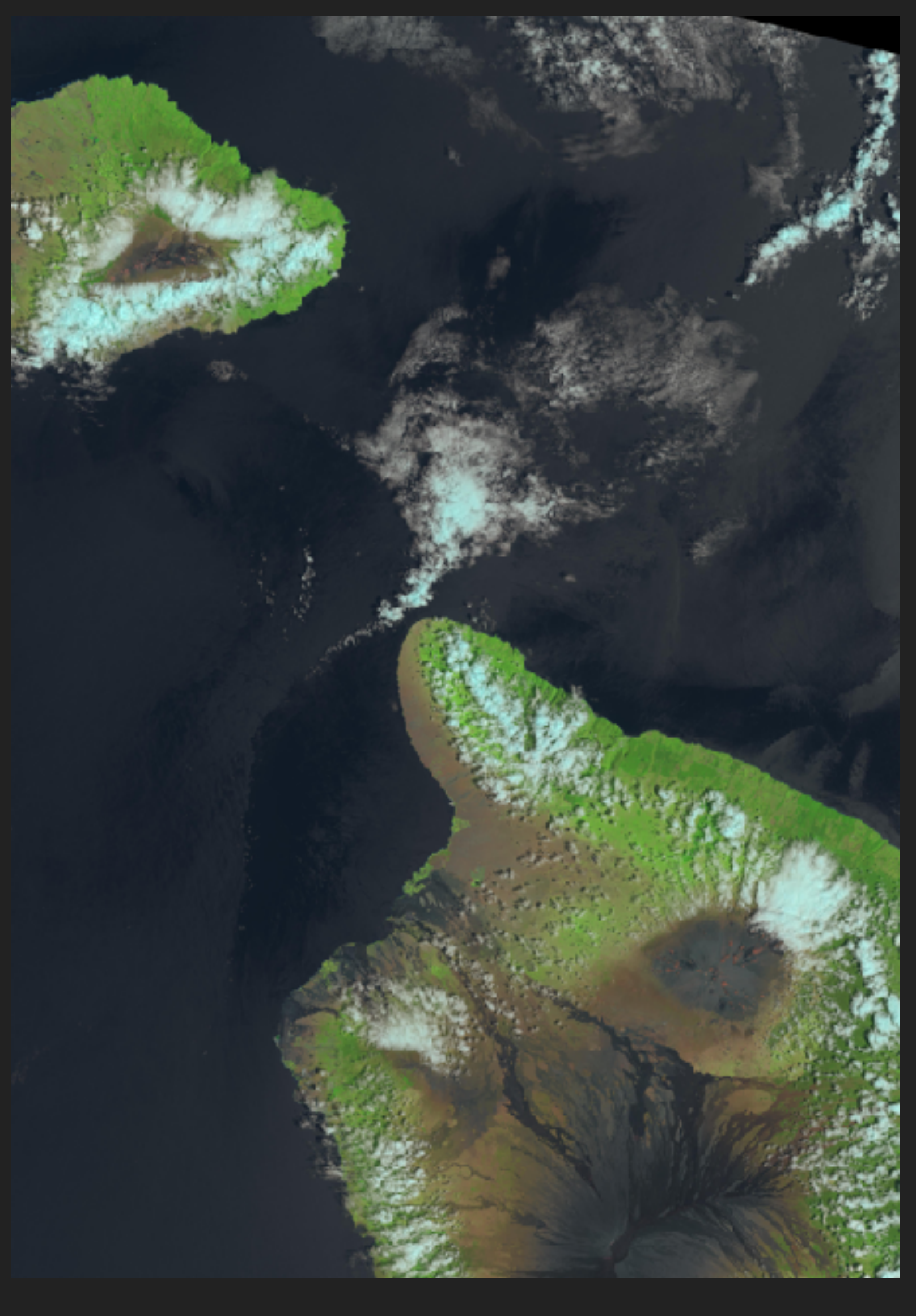

Visible (RGB)

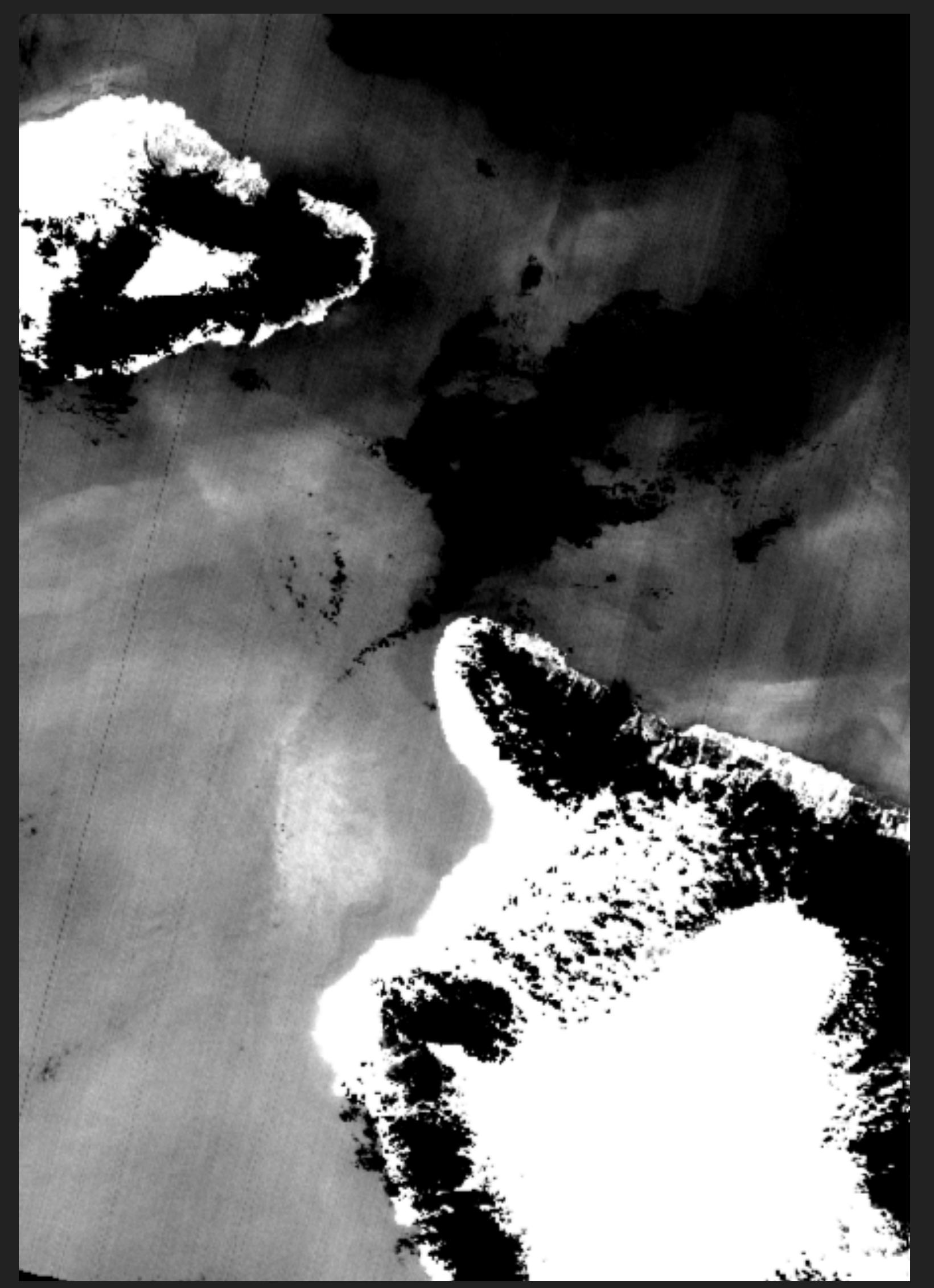

Thermal Infrared (TIR)

- Goal: better constrain locations of potential SGD occurrences

- Explore the links between SGD and changes in SST and OC through RS

- Map areas of PSGD and compare them with known locations 


\section{PRELIMINARY RESULTS}

- Ocean Color vs Sea Surface Temperature

v Experiments suggest that colder waters likely under the effect of SGD have different spectra (color)

- Coldest and warmest waters have less color variability

- Identified subset of colors per temperature interval

Temperature anomalies

- Automatic method

- Pinpoint locations
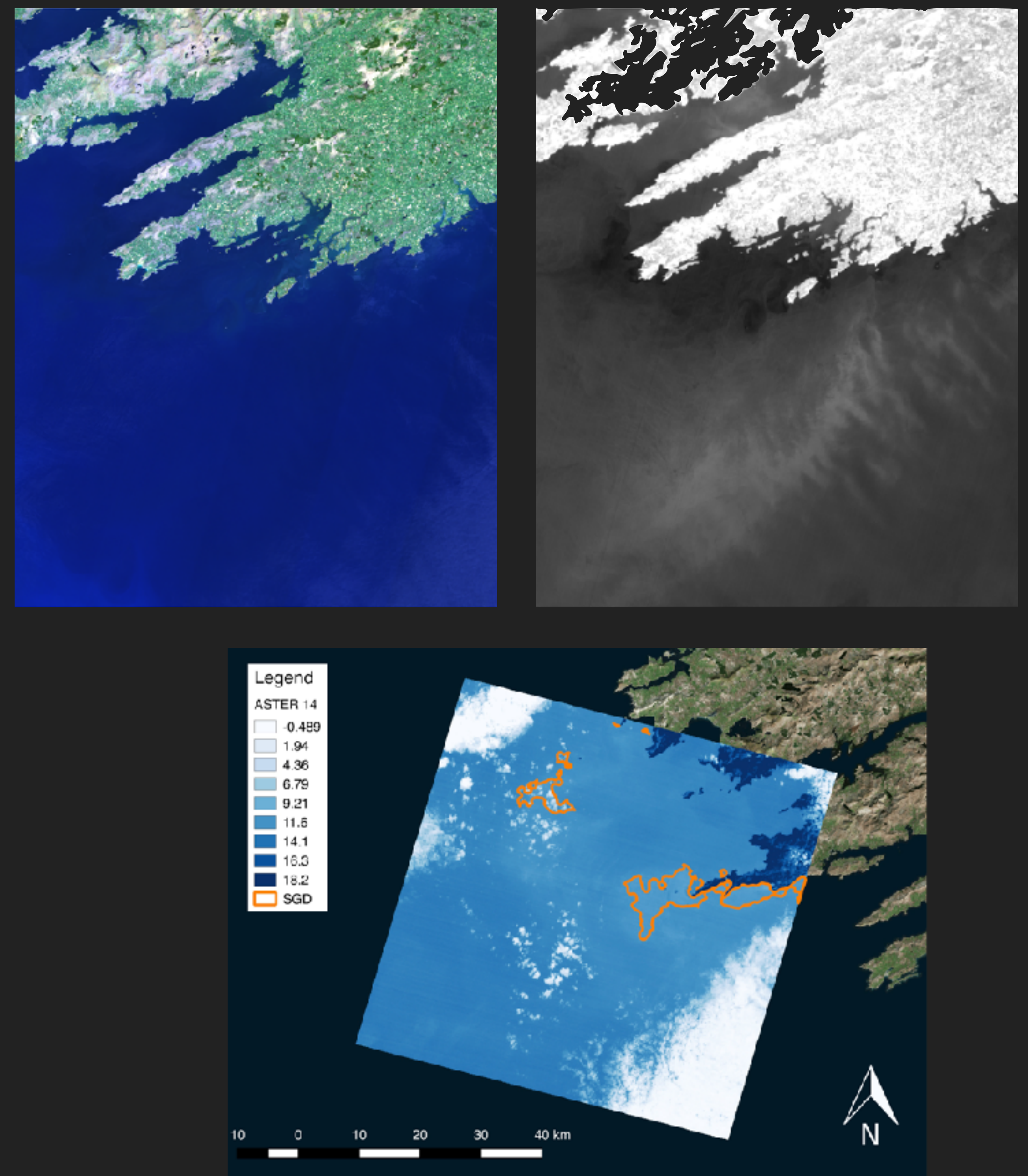
TEMPERATURE VS VISIBLE SPECTRA

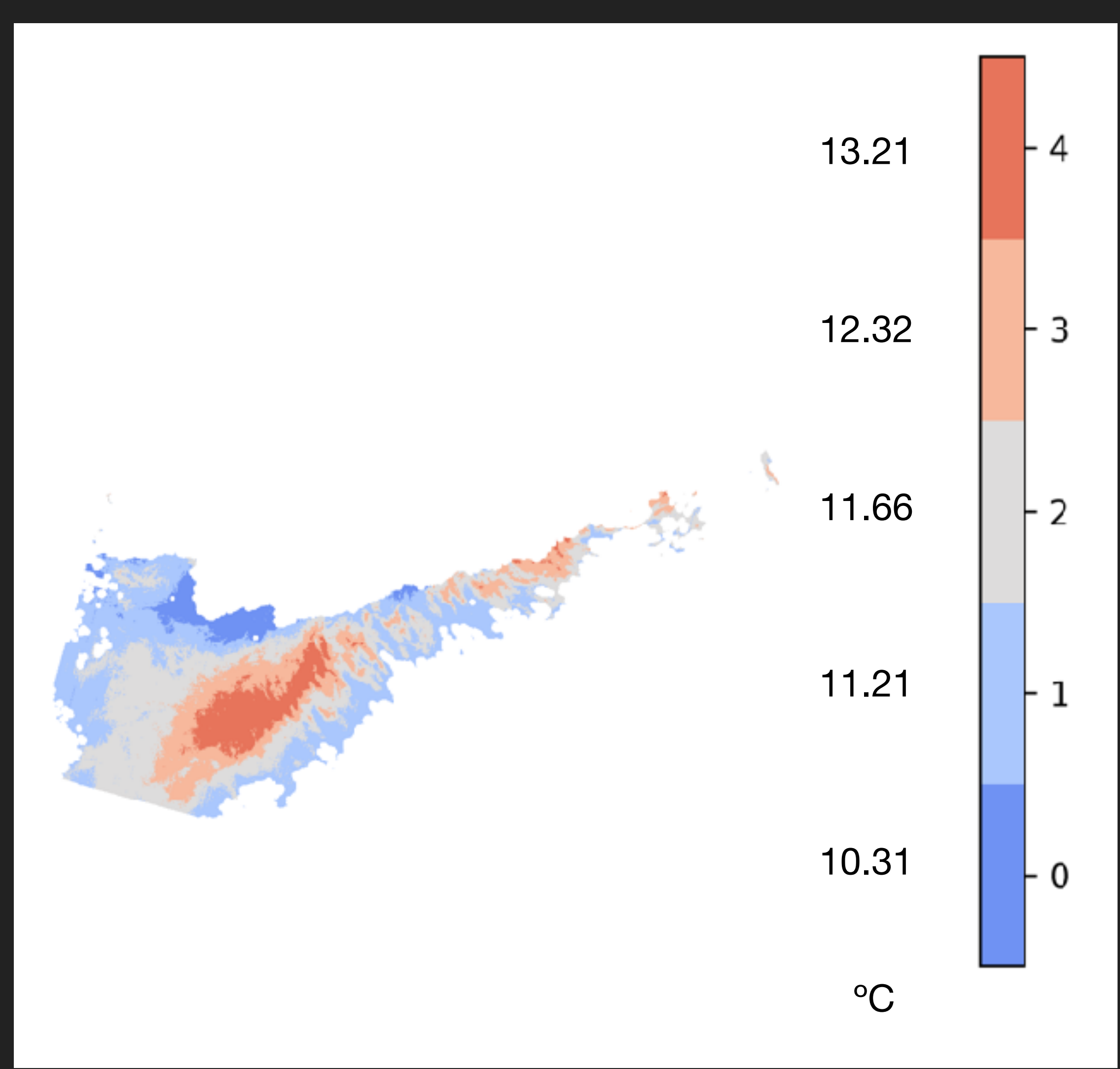

5 TIR ranges

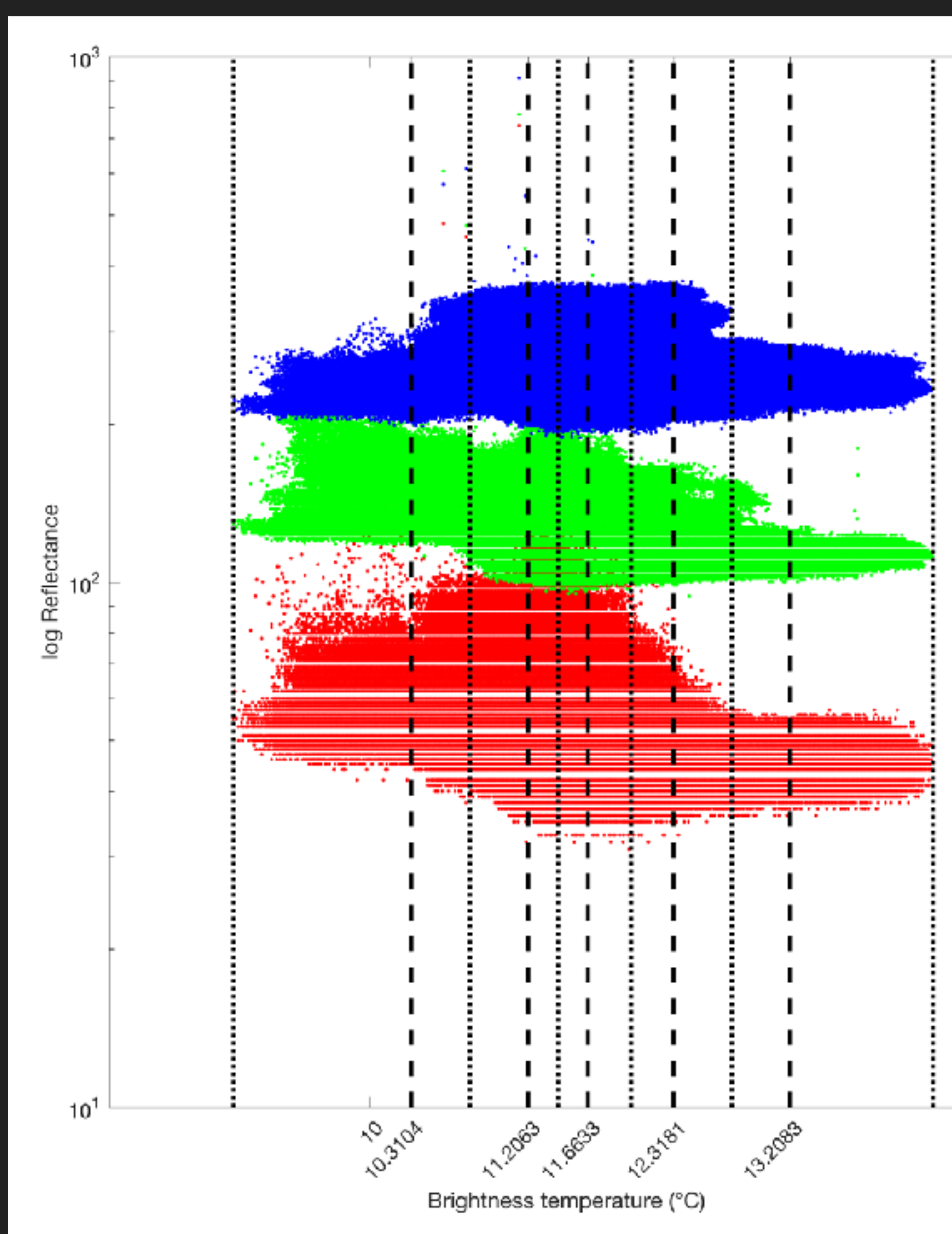

5 TIR ranges 


\section{TEMPERATURE VS VISIBLE SPECTRA}

- What colors are in each TIR range?

vuantize to 16 colors
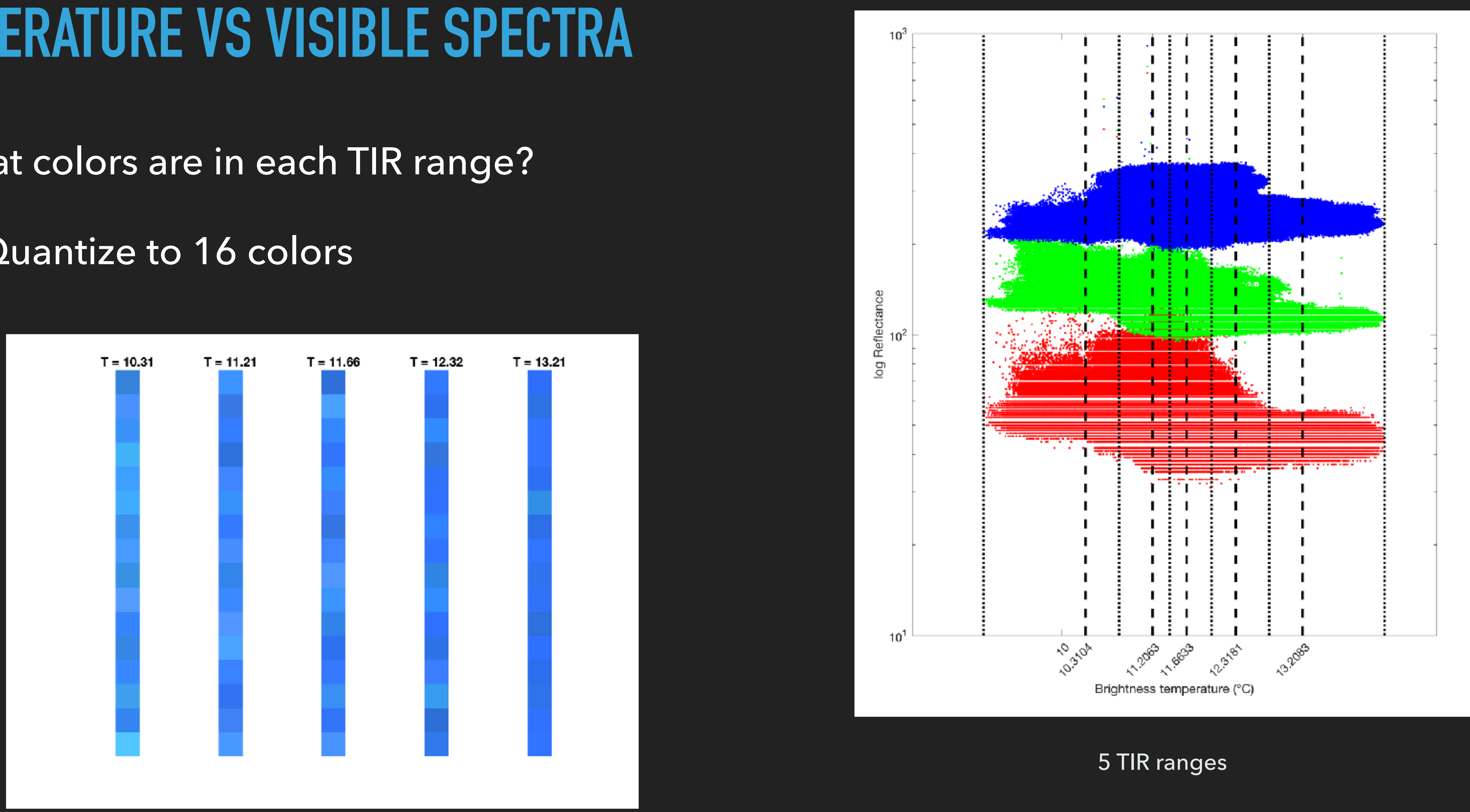

5 TIR ranges 


\section{DERIVATIVE SPECTROSCOPY}
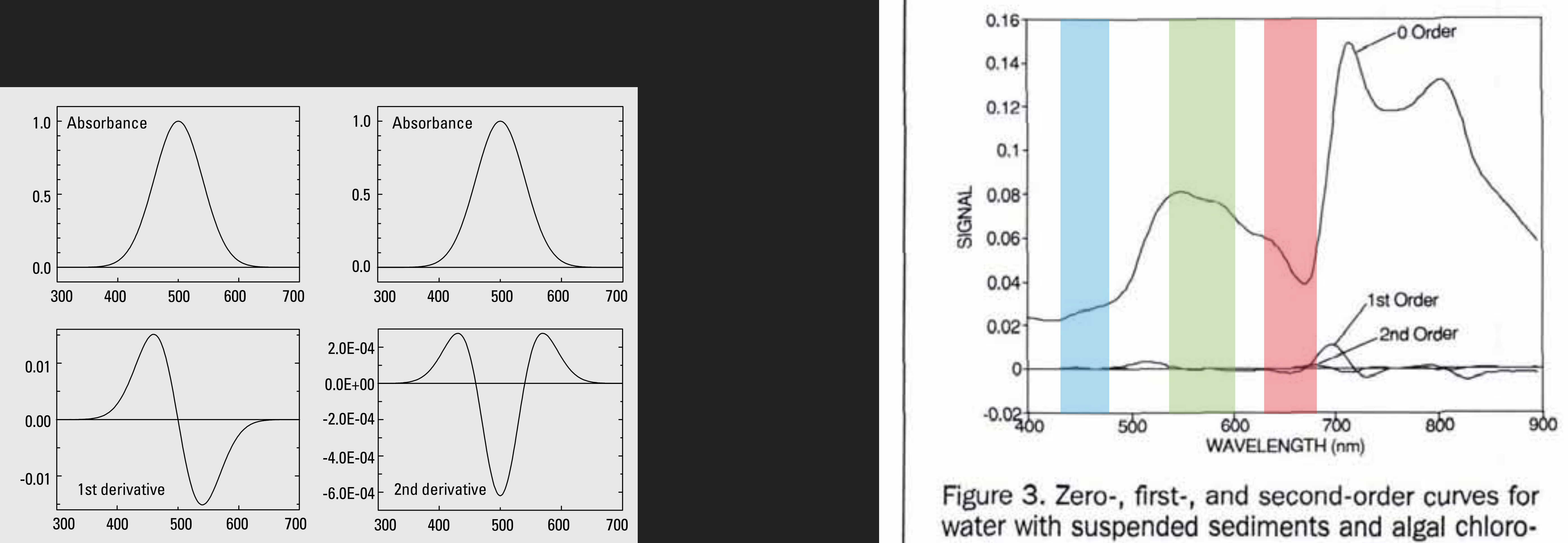

Figure 3. Zero-, first-, and second-order curves for water with suspended sediments and algal chlorophyll. 


\section{DERIVATIVE SPECTROSCOPY}

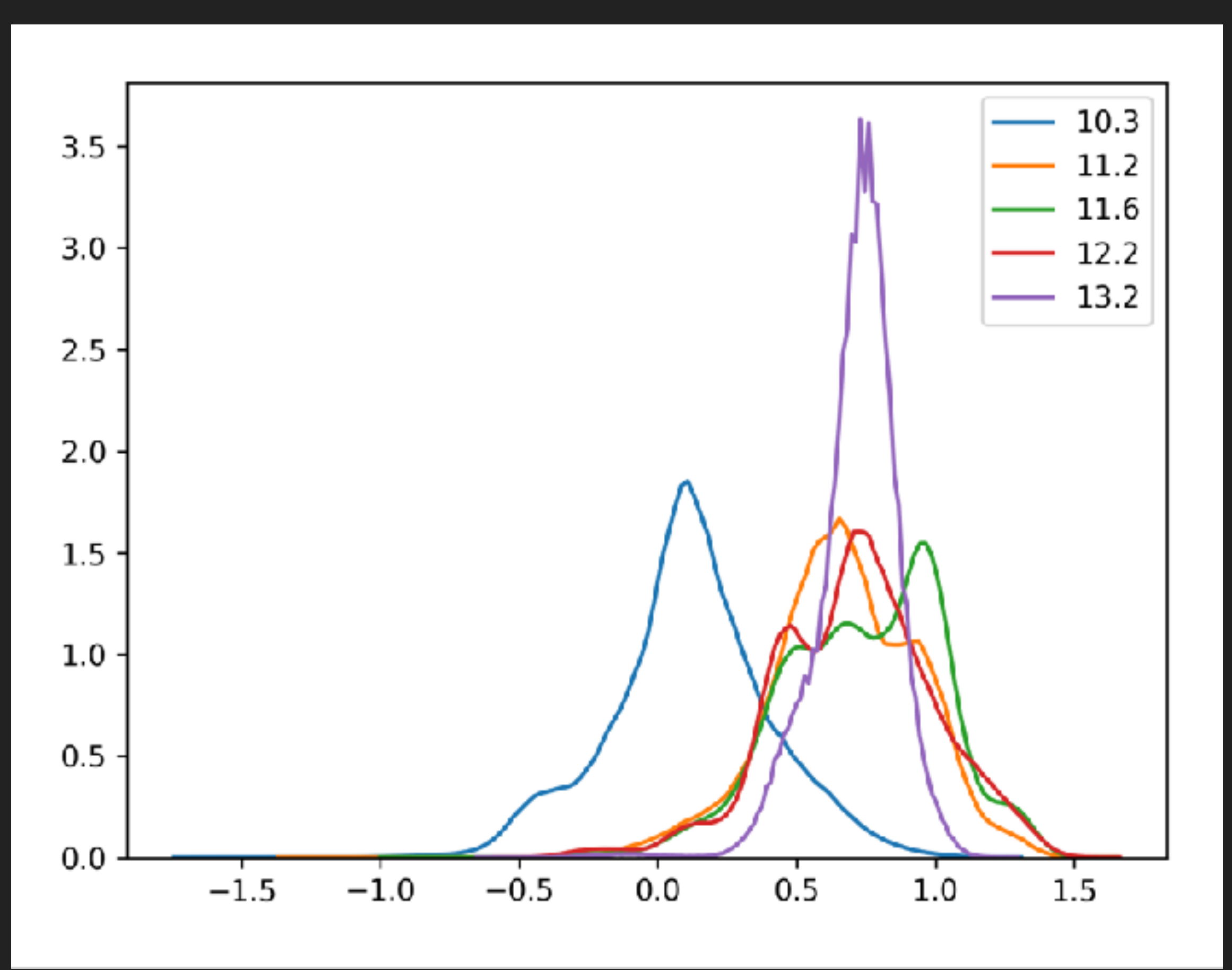

PDF of 2nd derivative per cluster

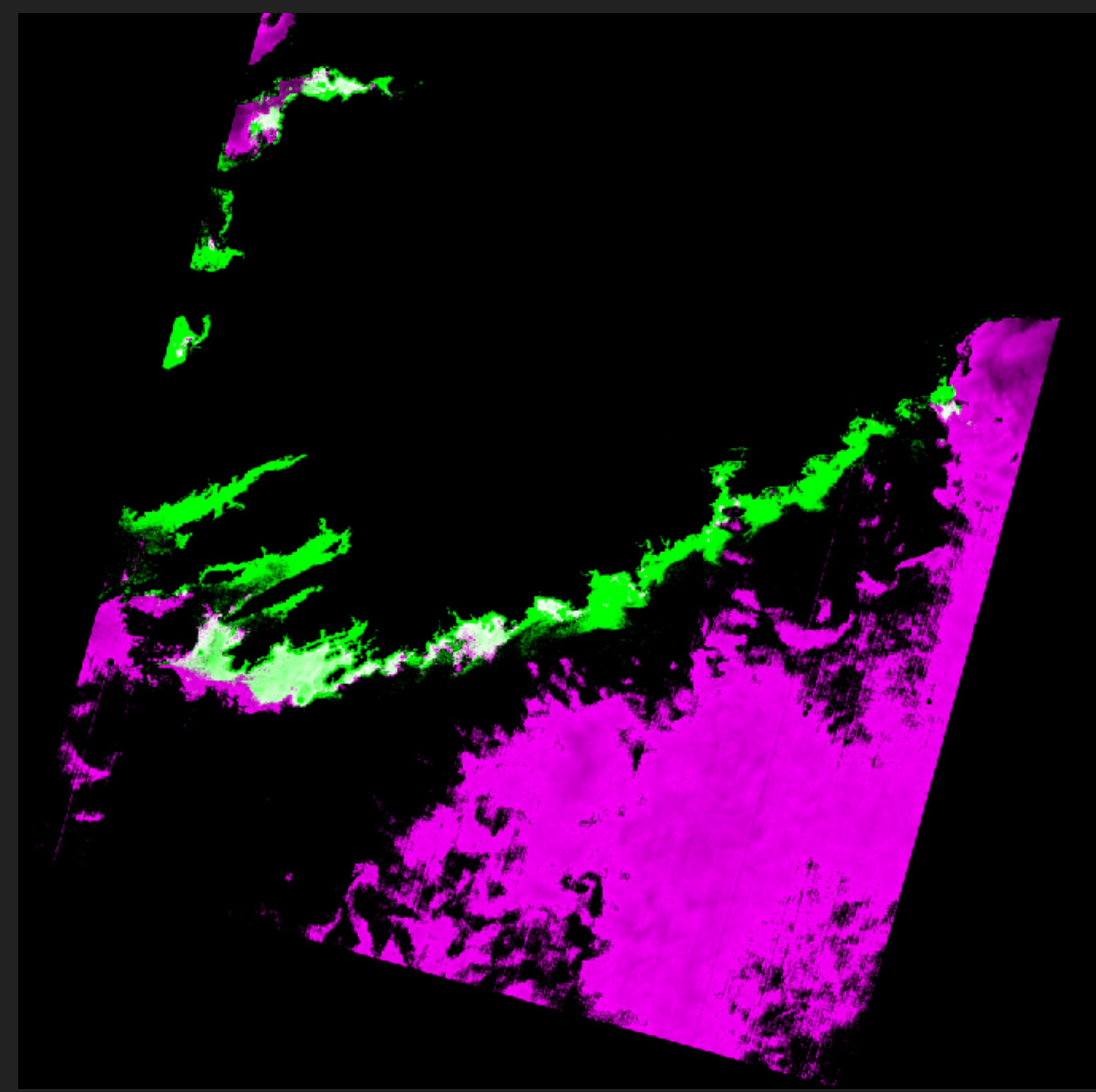

Green: Change of signal in the 2 nd derivative Purple: temperature lower than the mean White: both conditions 


\section{CHALLENGES AND LIMITATIONS}

Limitations

Dxperiment with other locations and seasons

Define clustering steps, further analyze descriptors

- Focus on coastal areas, where SGD is more likely to occur

- Limited matching with the expected (lab) spectrum

Possible solutions

more bands/coverage over the red-edge 


\section{CASE STUDY}

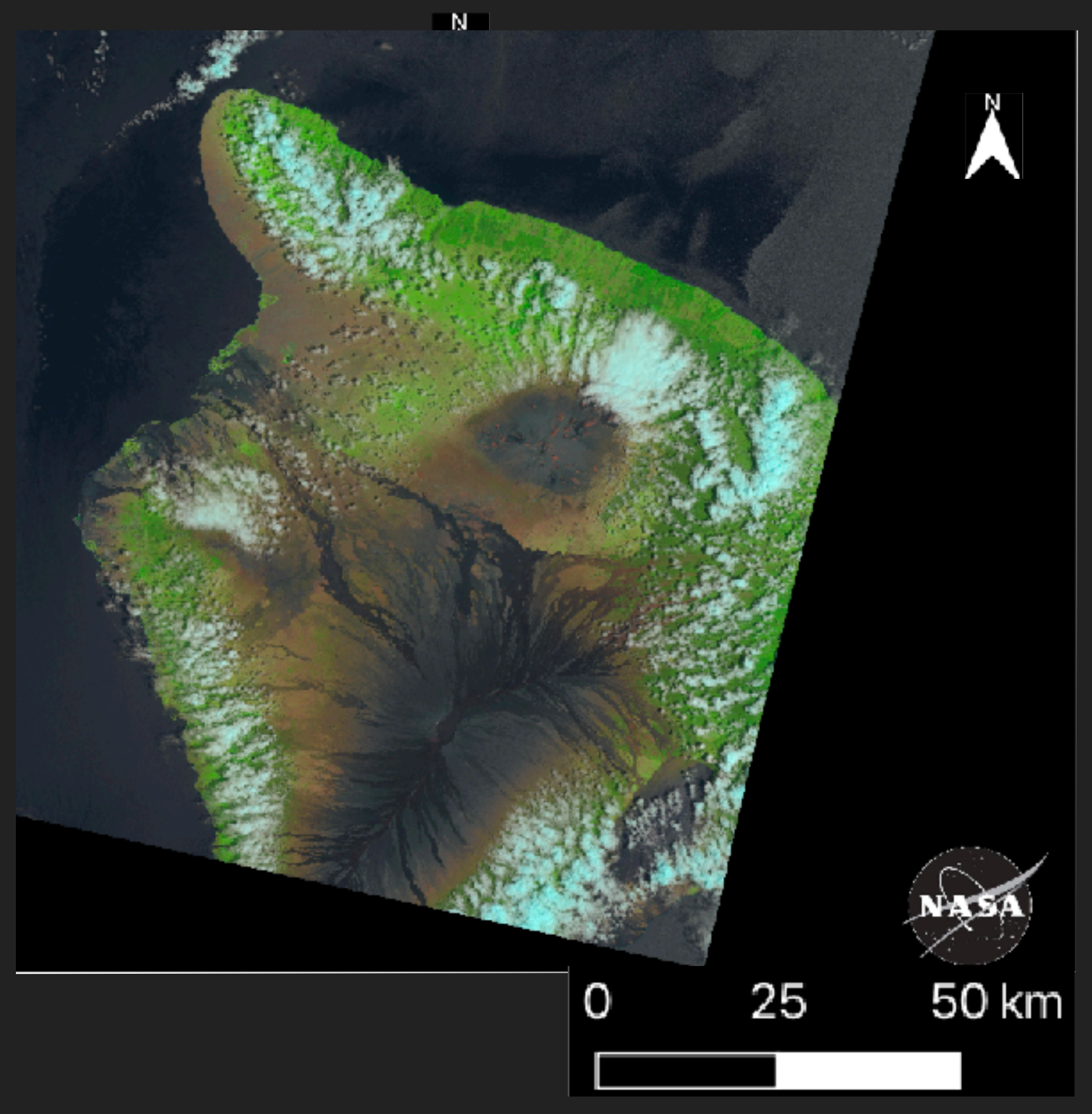

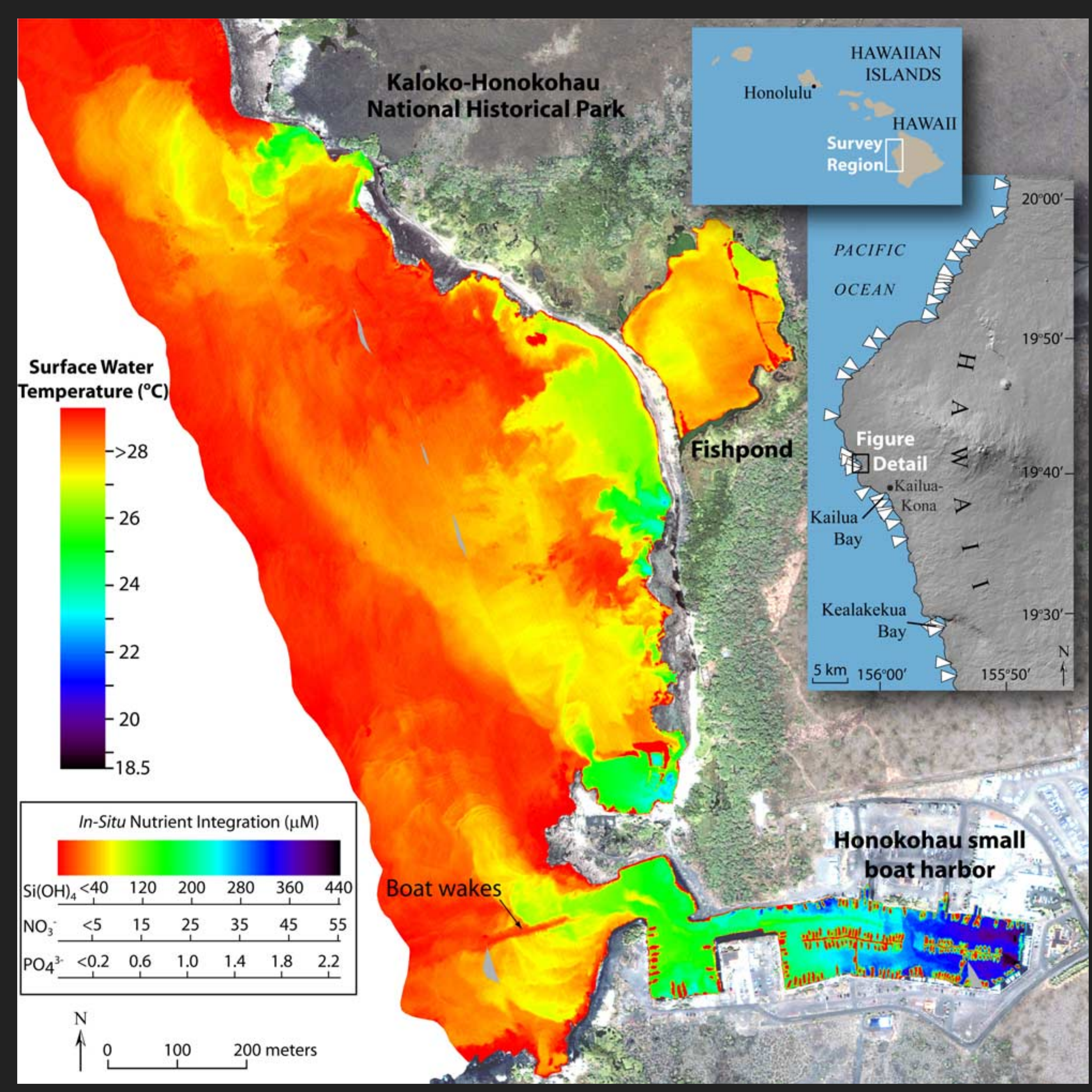

Adapted from Johnson et al., 2008 


\section{CASE STUDY}

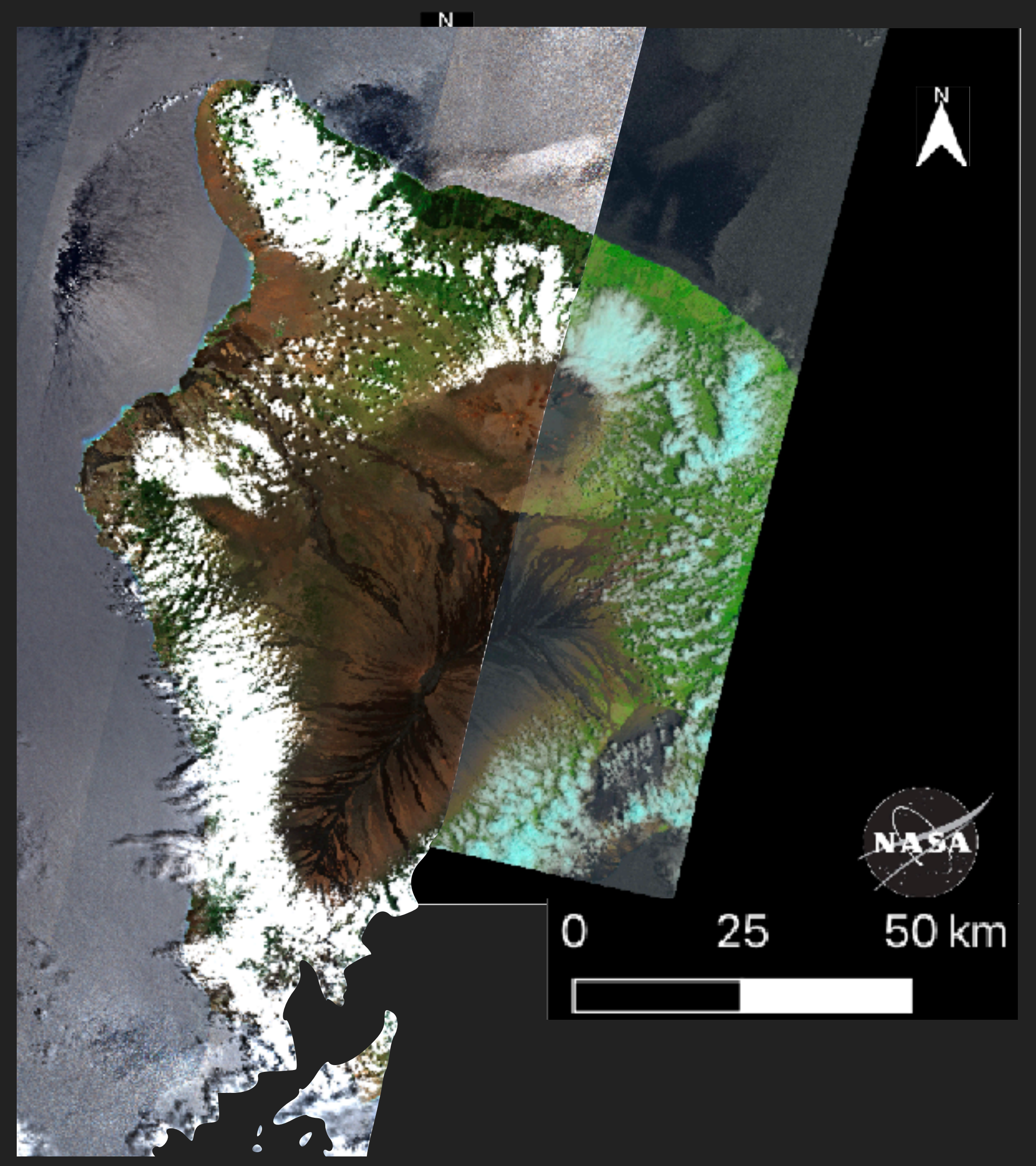

Landsat 8 2019-04-06 20:42:41 UTC

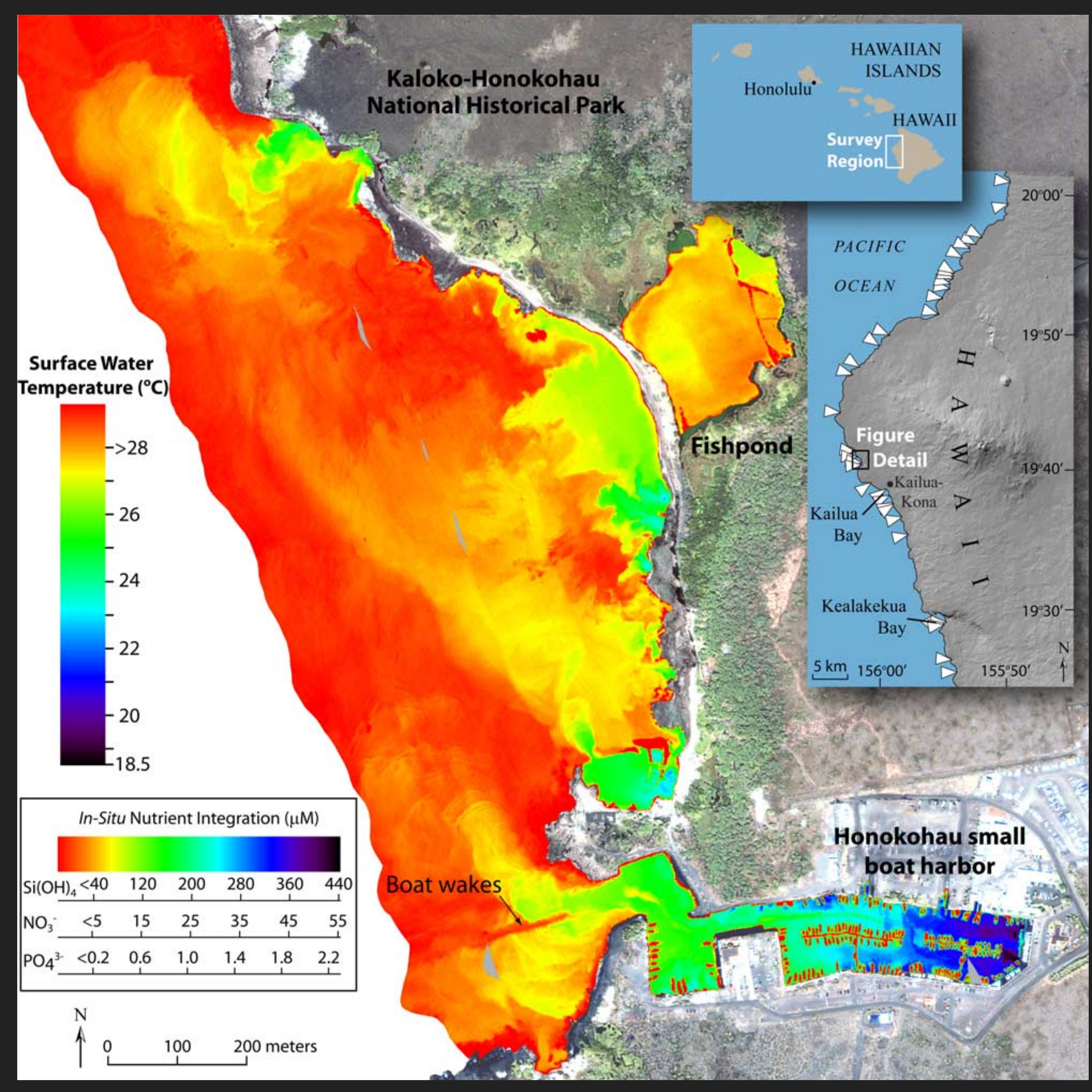

Adapted from Johnson et al., 2008

Sentinel-2A 2019-04-06 21:05:51 UTC 
TEMPERATURE VS VISIBLE SPECTRA
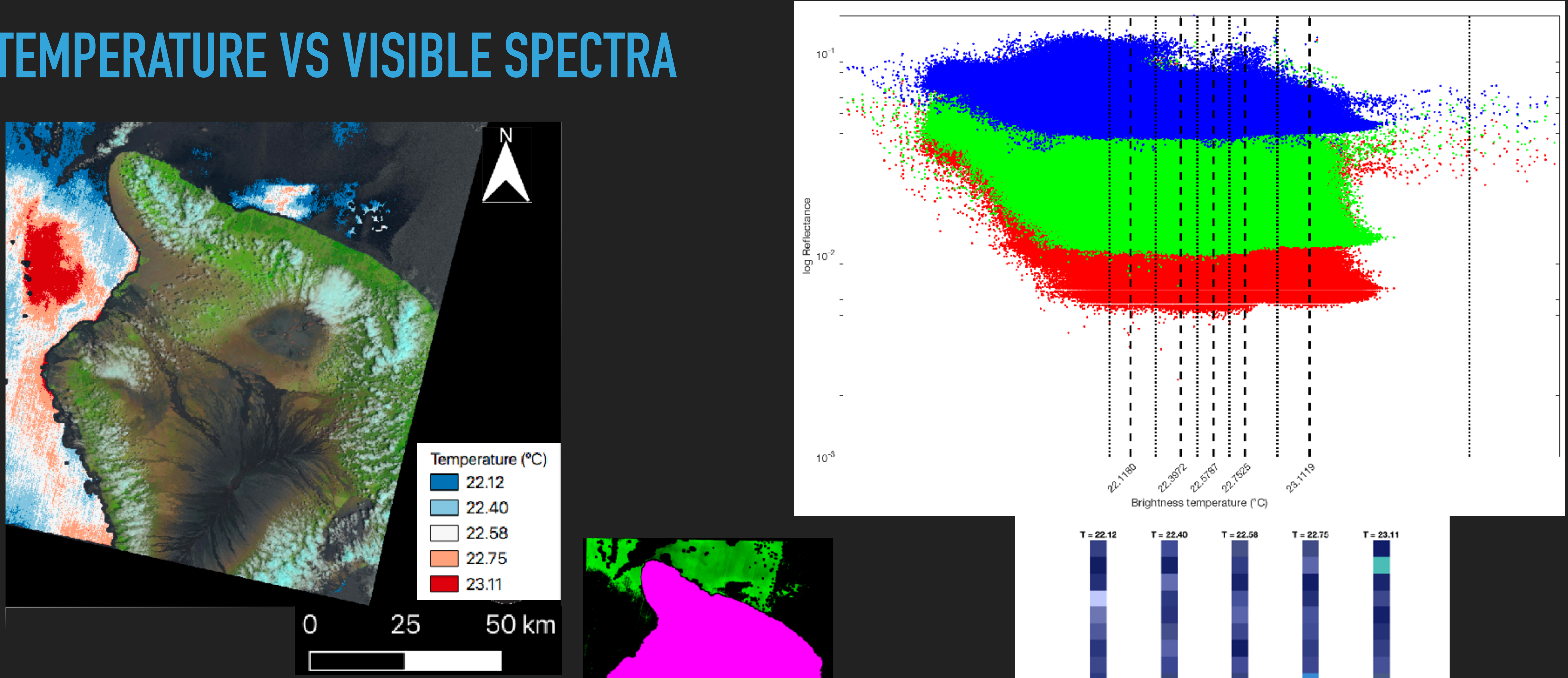

Temperature below average
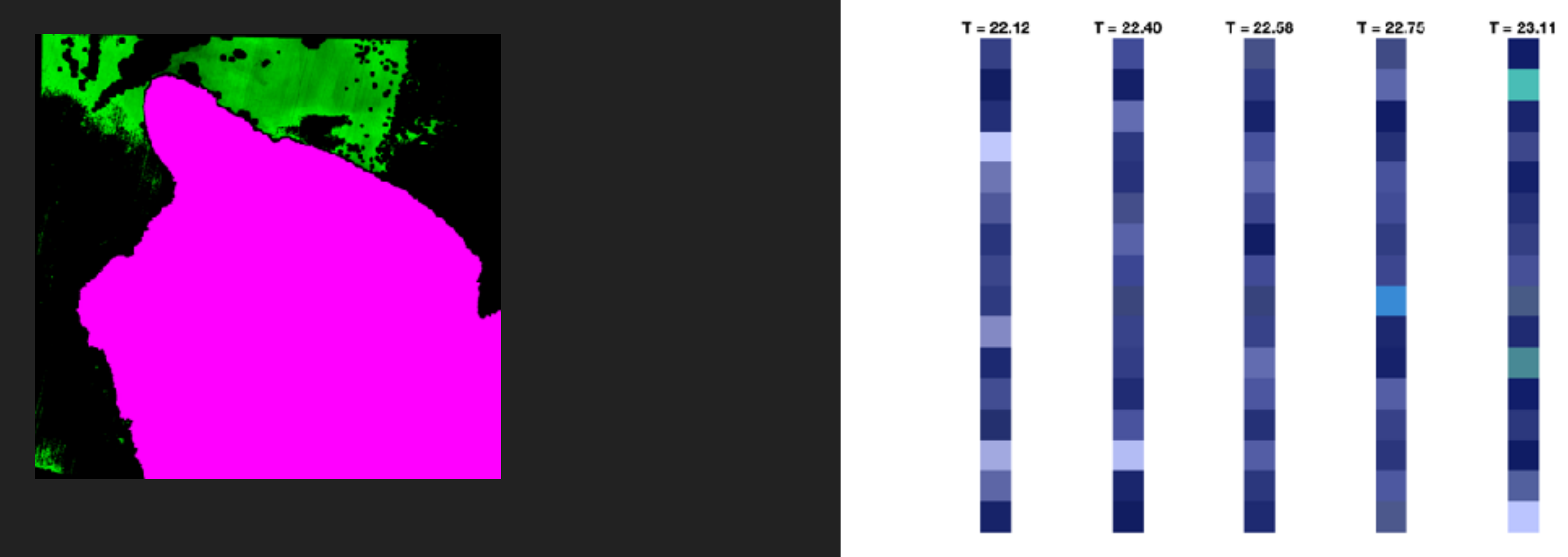


\section{DERIVATIVE SPECTROSCOPY — LANDSAT 8 VS SENTINEL 2}

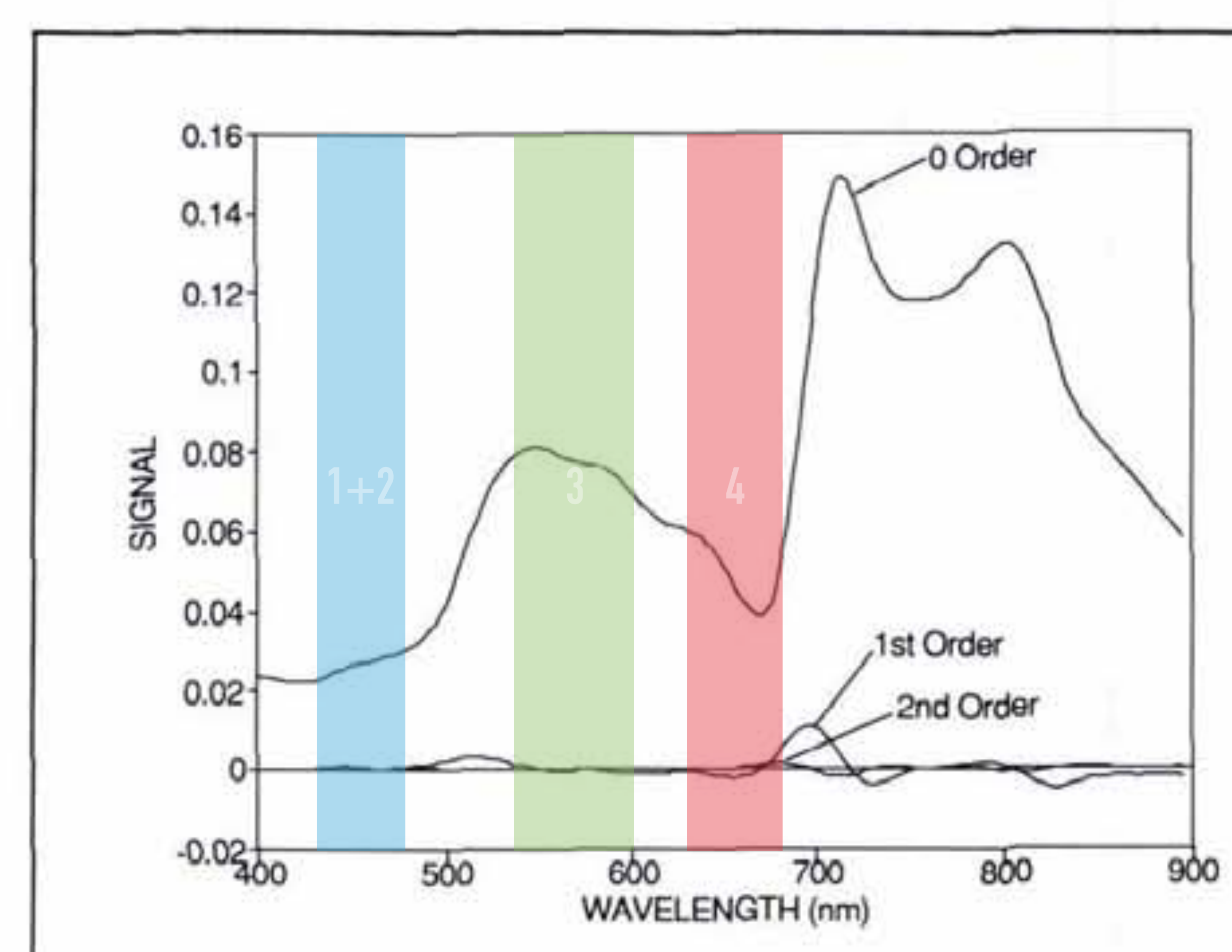

Figure 3. Zero-, first-, and second-order curves for water with suspended sediments and algal chlorophyll.

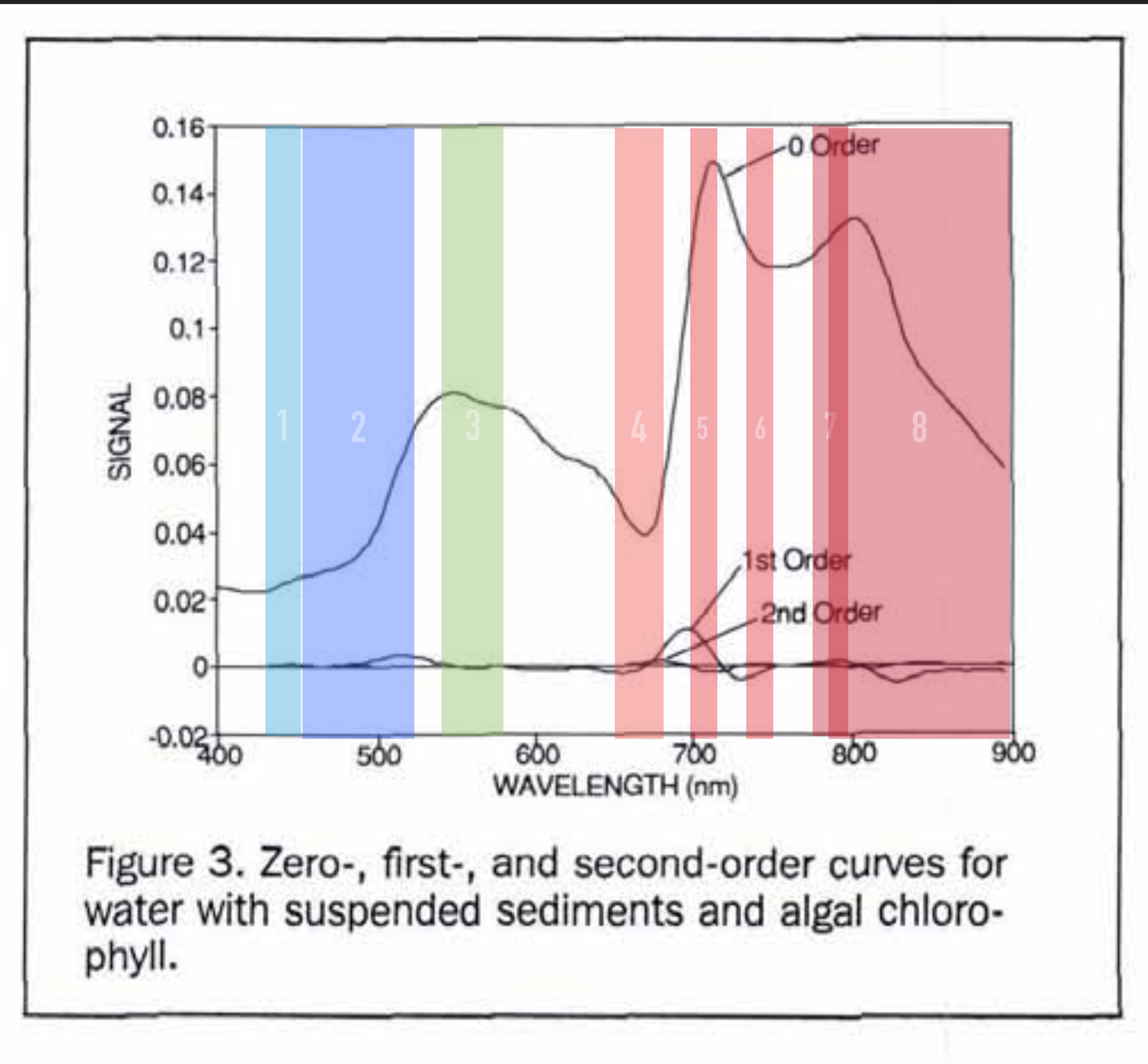

Adapted from Goodin et al., 1993 


\section{DERIVATIVE SPECTROSCOPY — LANDSAT 8 VS SENTINEL 2}

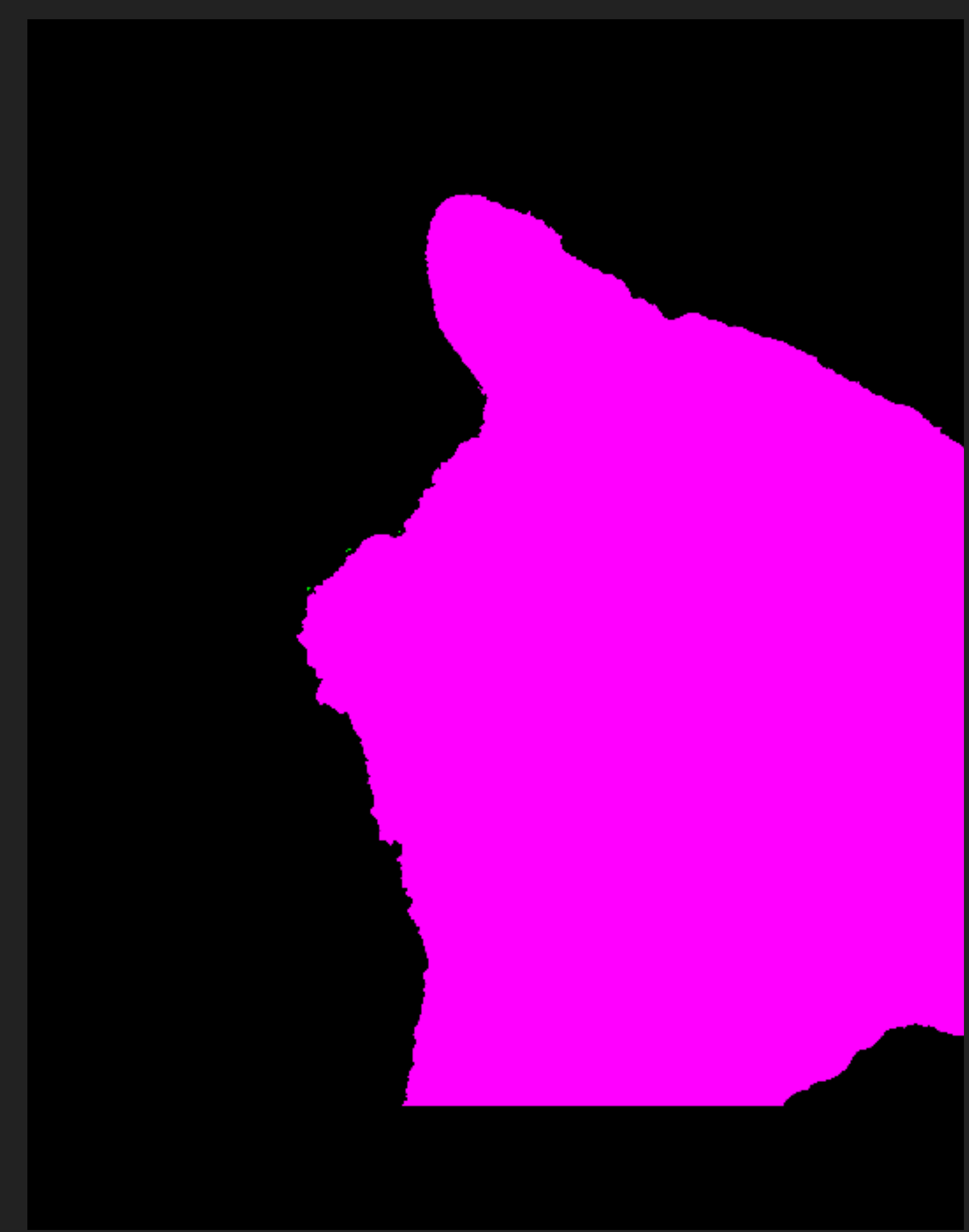

Landsat 8 (3-4)

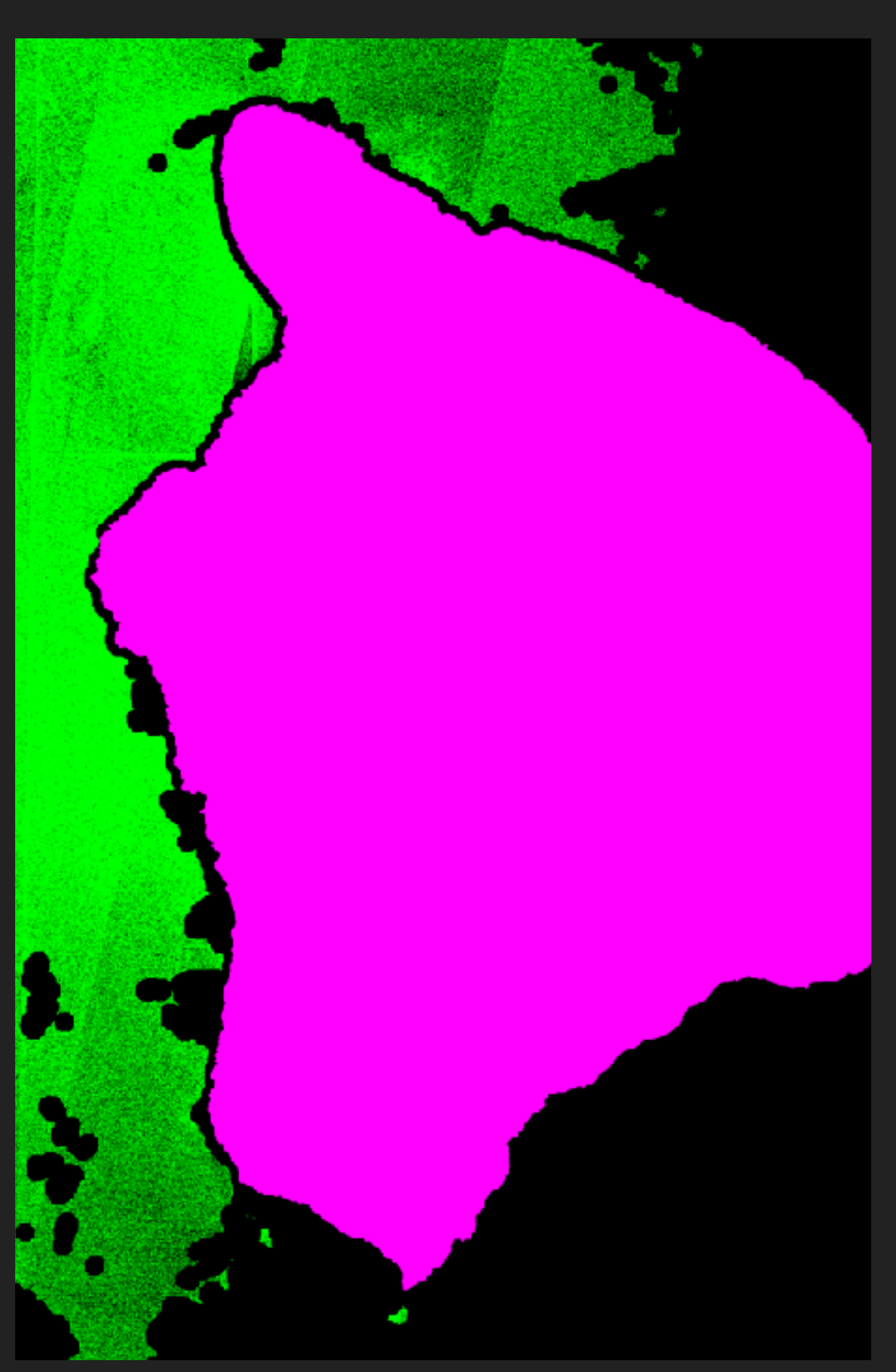

Sentinel 2 (3-4)

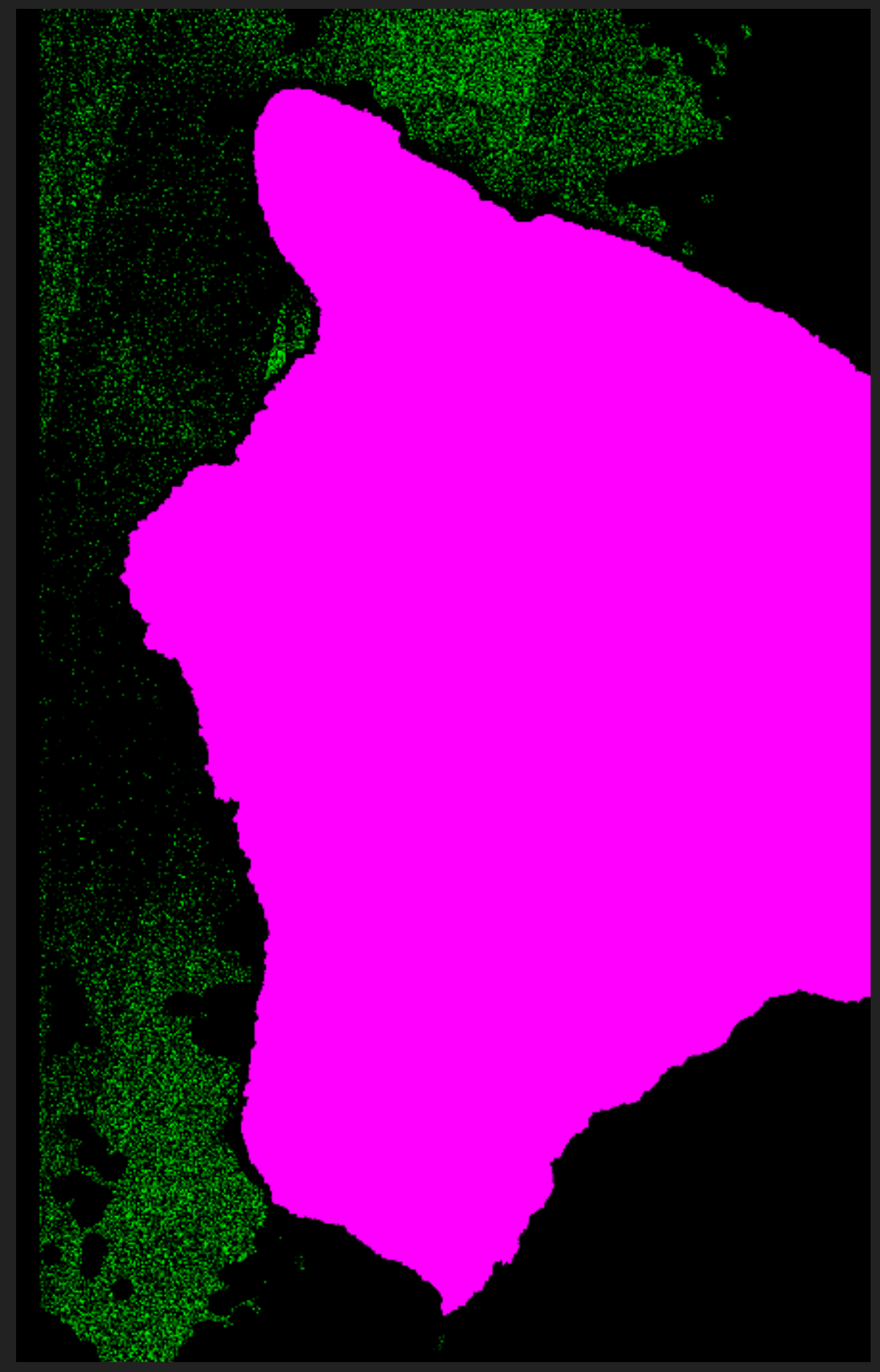

Sentinel 2 (4-5) 


\section{SPECTRAL ANGLE MAPPER}
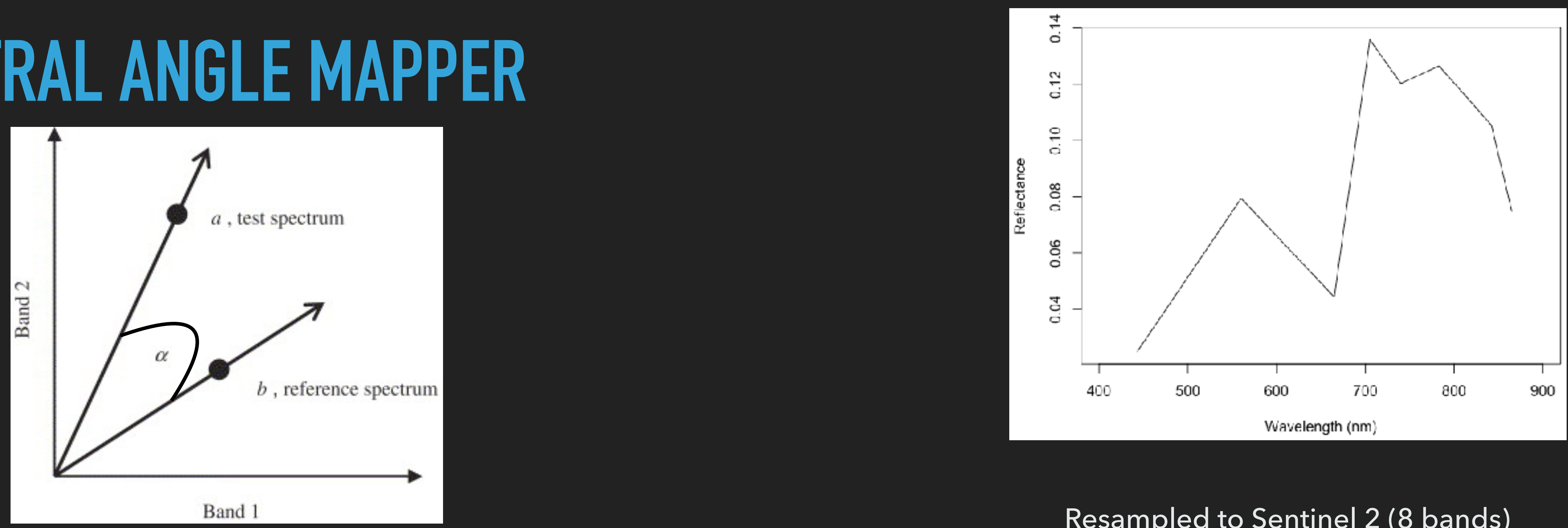

Resampled to Sentinel 2 ( 8 bands)

Adapted from Park et al.. 2007

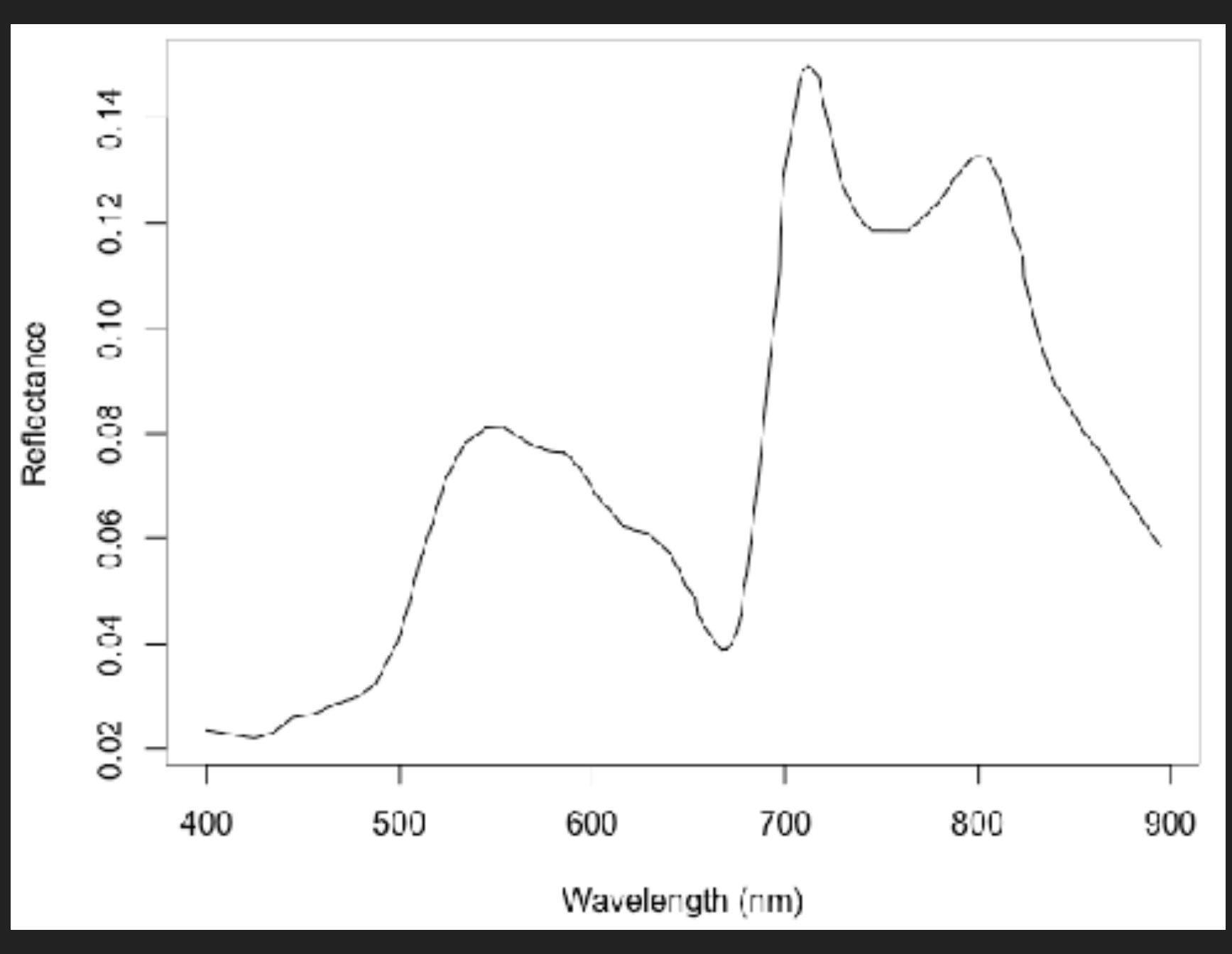

Adapted from Goodin et al., 1993

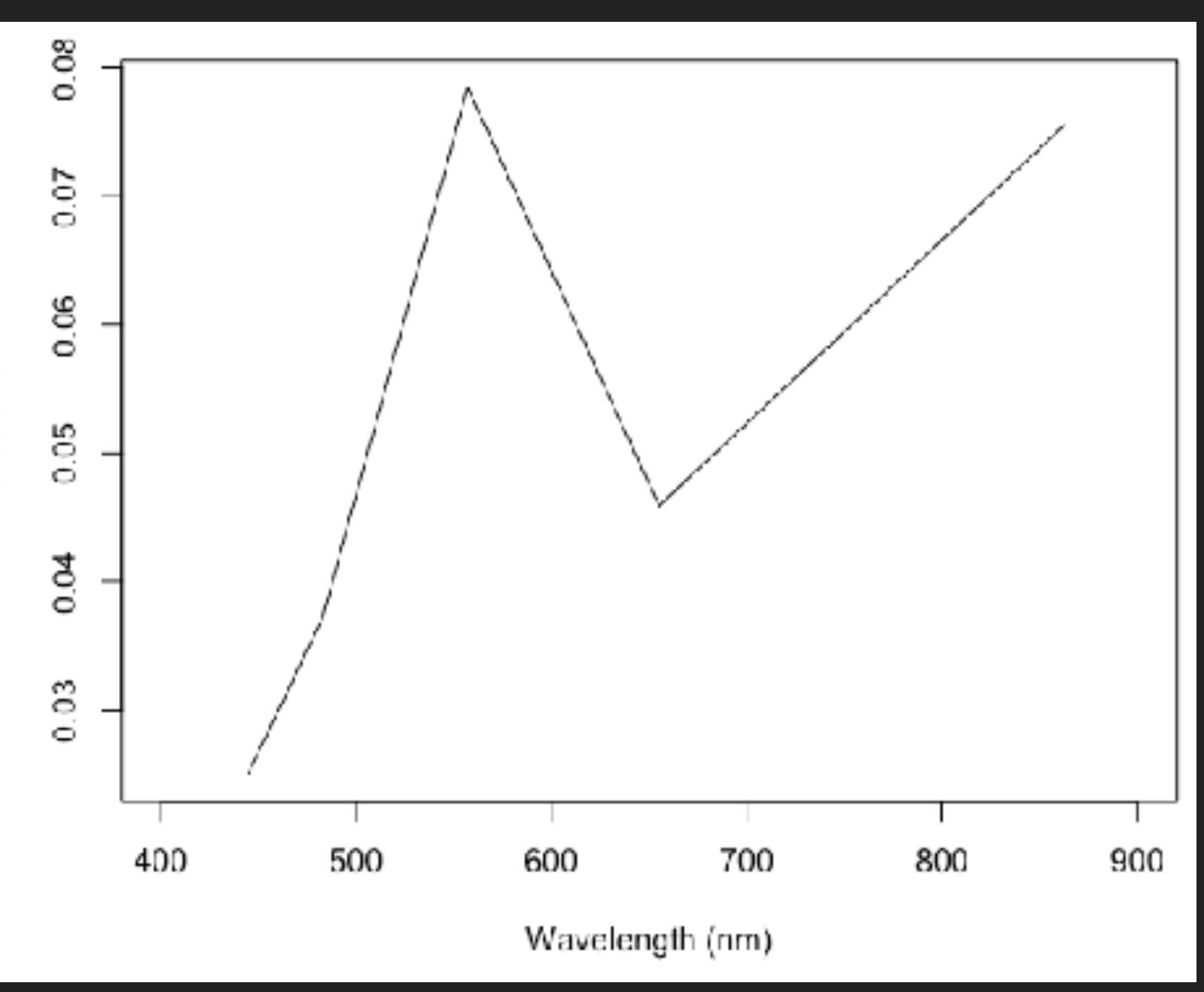

Resampled to Landsat 8 (5 bands) 


\section{SPECTRAL ANGLE MAPPER}

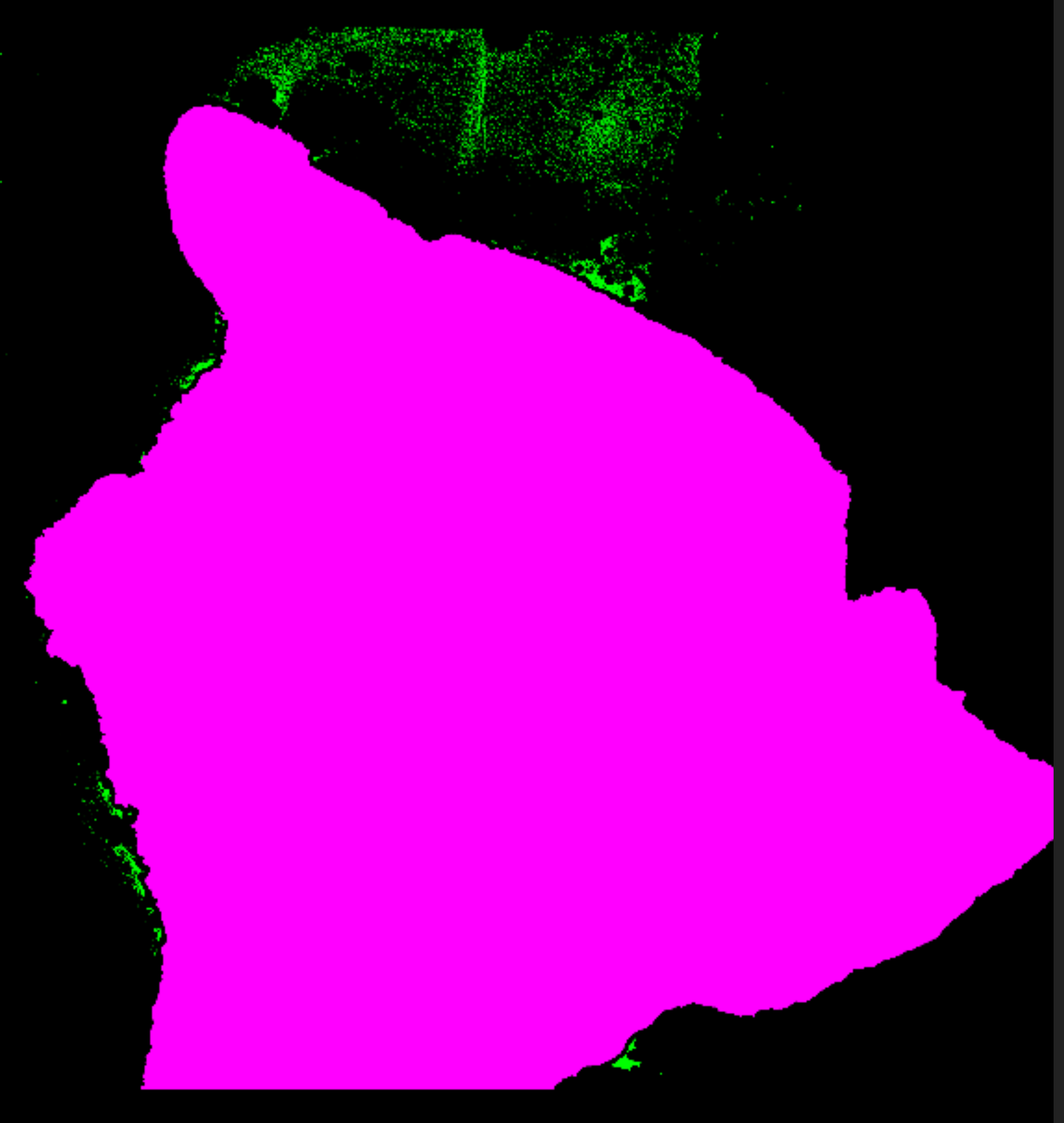

Landsat 8

Lowest 5\% SAM

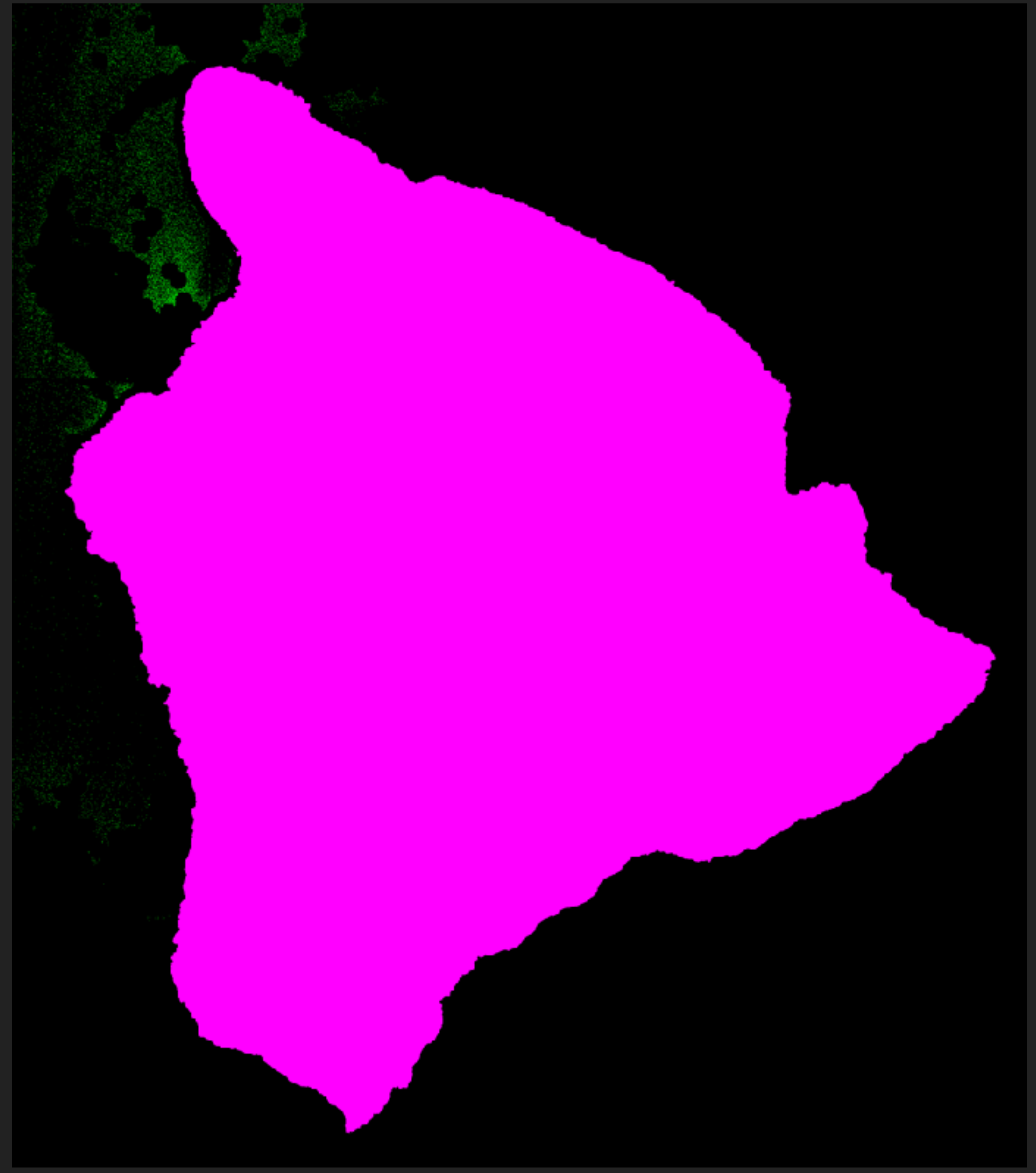

Sentinel 2

Lowest 5\% SAM 


\section{SPECTRAL ANGLE MAPPER}

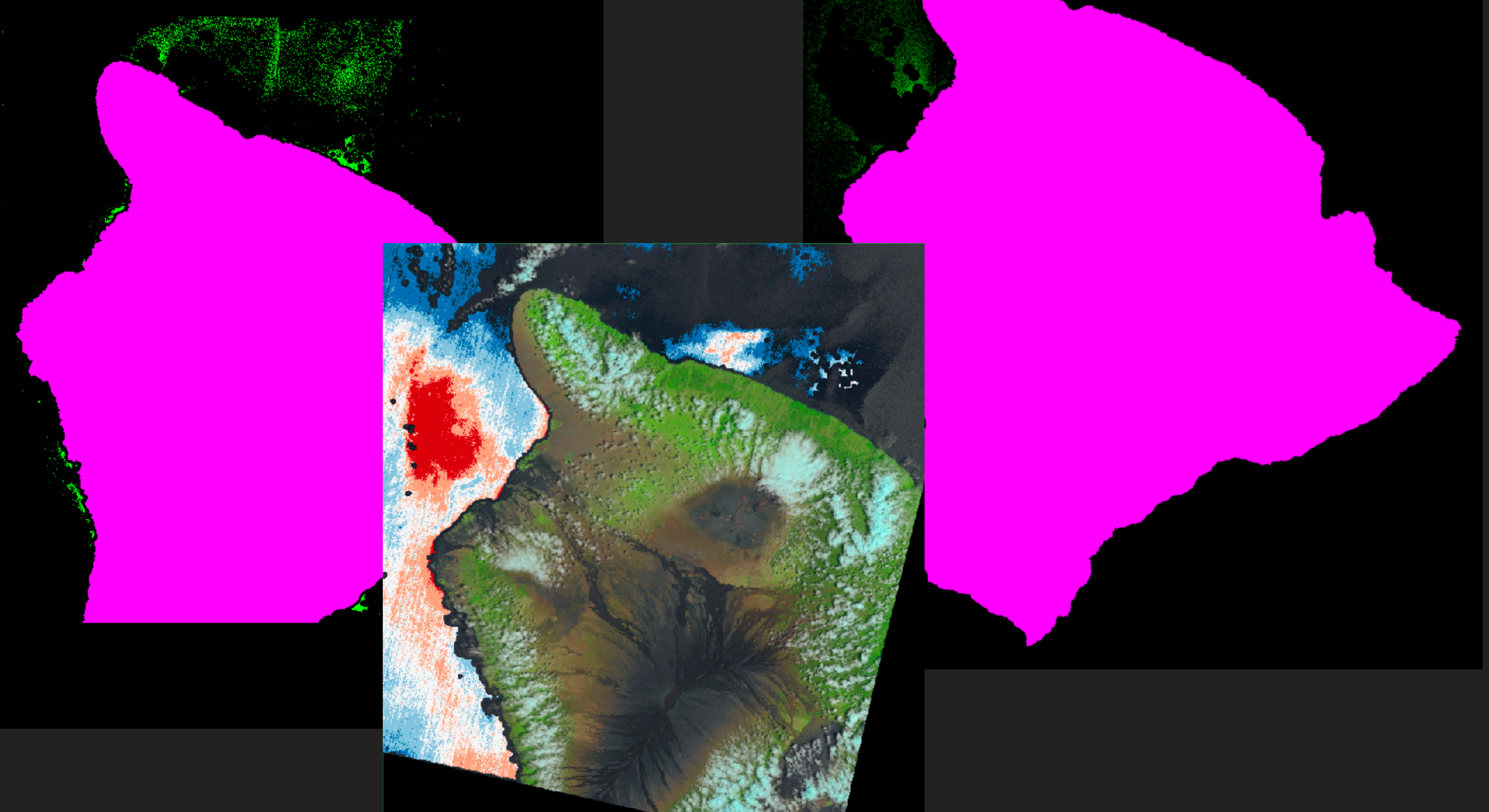




\section{SPECTRAL ANGLE MAPPER}

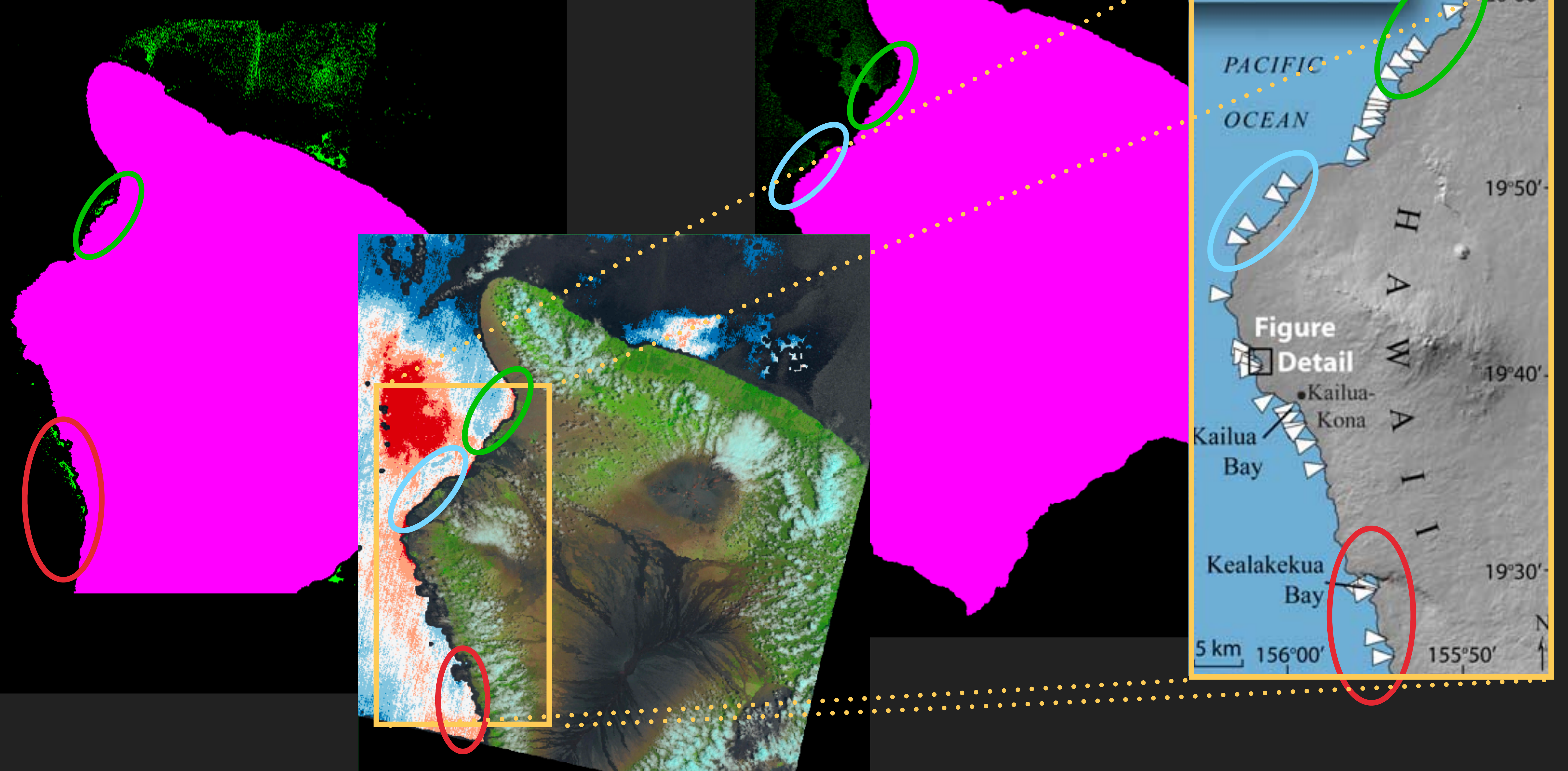




\section{MAIN FINDINGS}

Ocean Color vs Sea Surface Temperature

- More bands / spectra coverage may help to improve certainty

- Time-coinciding TIR imagery is beneficial

- Cold plumes may not be the coldest in the scene, but they are still colder than surrounding waters

- Angular distance more robust than change of signal of the derivative

\section{LIMTAATIONS / NEXT STEPS}

Missing other areas of potential SGD

- There are limited close joint-overpasses between L8 and S2

D Just one target spectrum particular to a limited and controlled area

- Experiment with other spectra
- Tackle areas where upwelling events are common

- Integrate currents and wind data

- Quantitative validation and uncertainty quantification

- Use existing ground truth data 



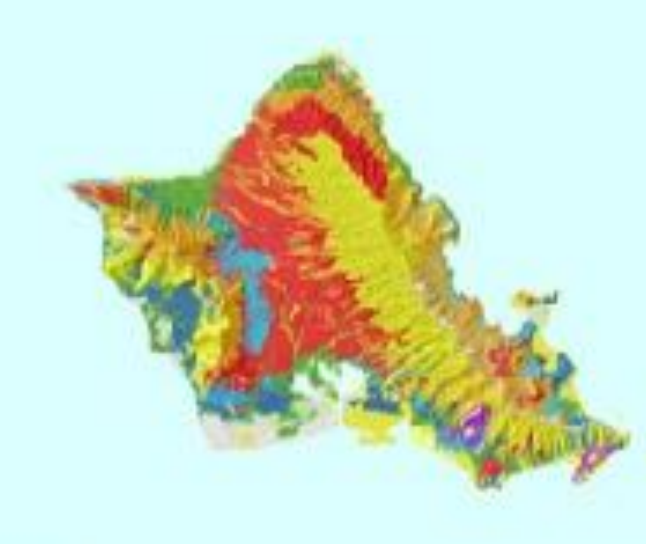

\section{Soil Orders}

Unclassified

Andisols

Aridisols

Entisols

Histosols

Inceptisols

Mollisols

Oxisols

Spodosols

Ultisols

Vertisols

Projection: NAD 1983, UTM Zone 4N

Source: Soil Survey Data - USDA Natural Resources Conservation Service

Digital Elevation Model - National Centers for Coastal Ocean Science

intry

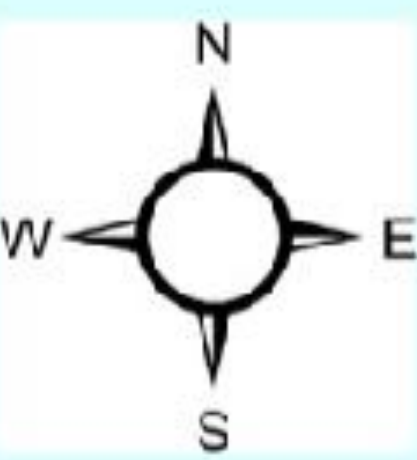

$-1$

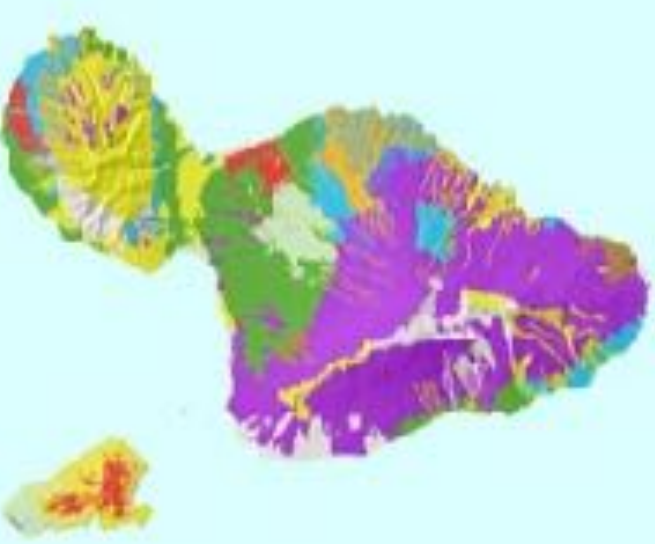

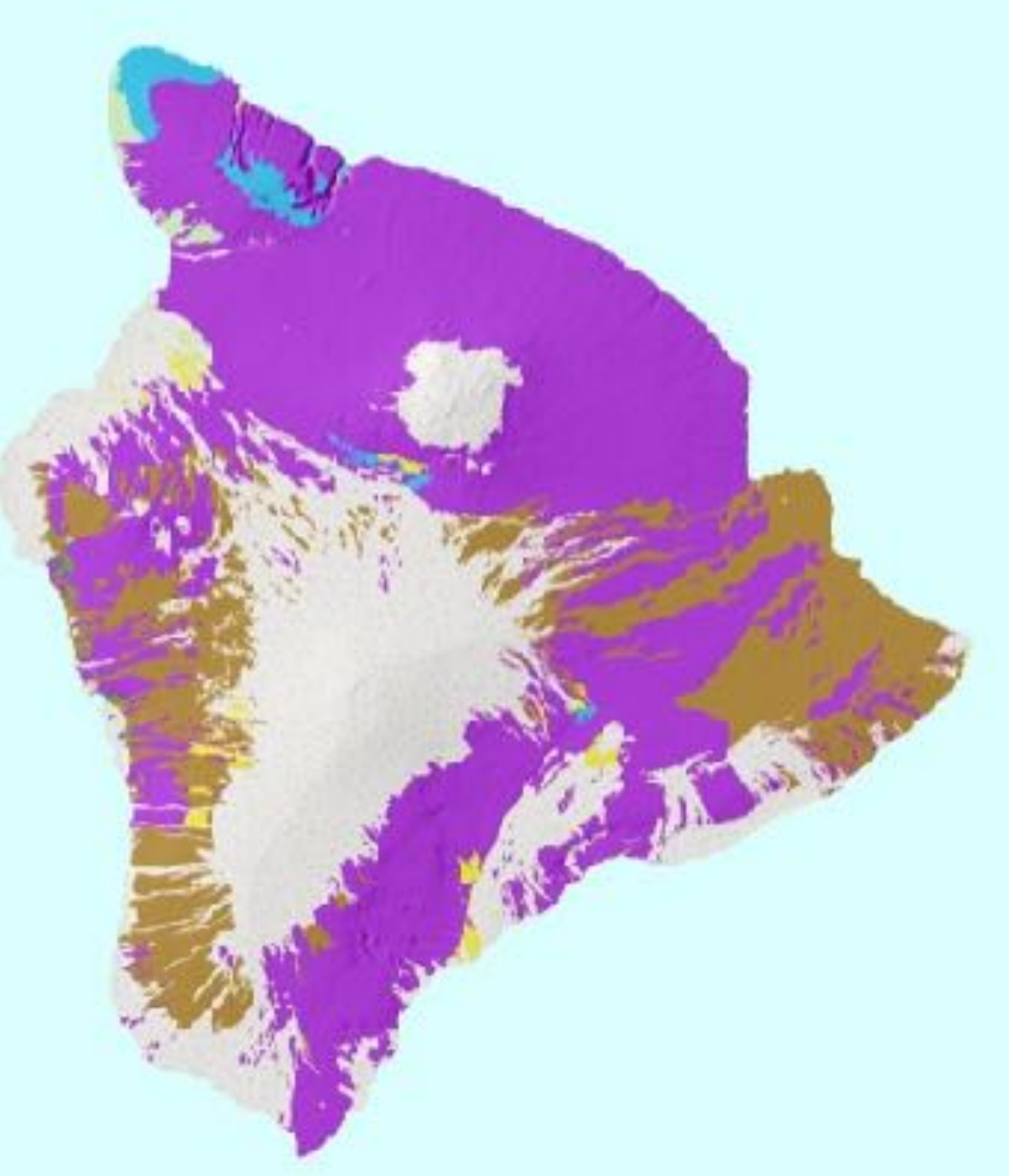


"Colored" bays were being masked as belonging to areas with medium probability clouds (green px on the figure in the right). Left figure: true color image overlayed with classification (light green is medium prob cloud; blue is water)

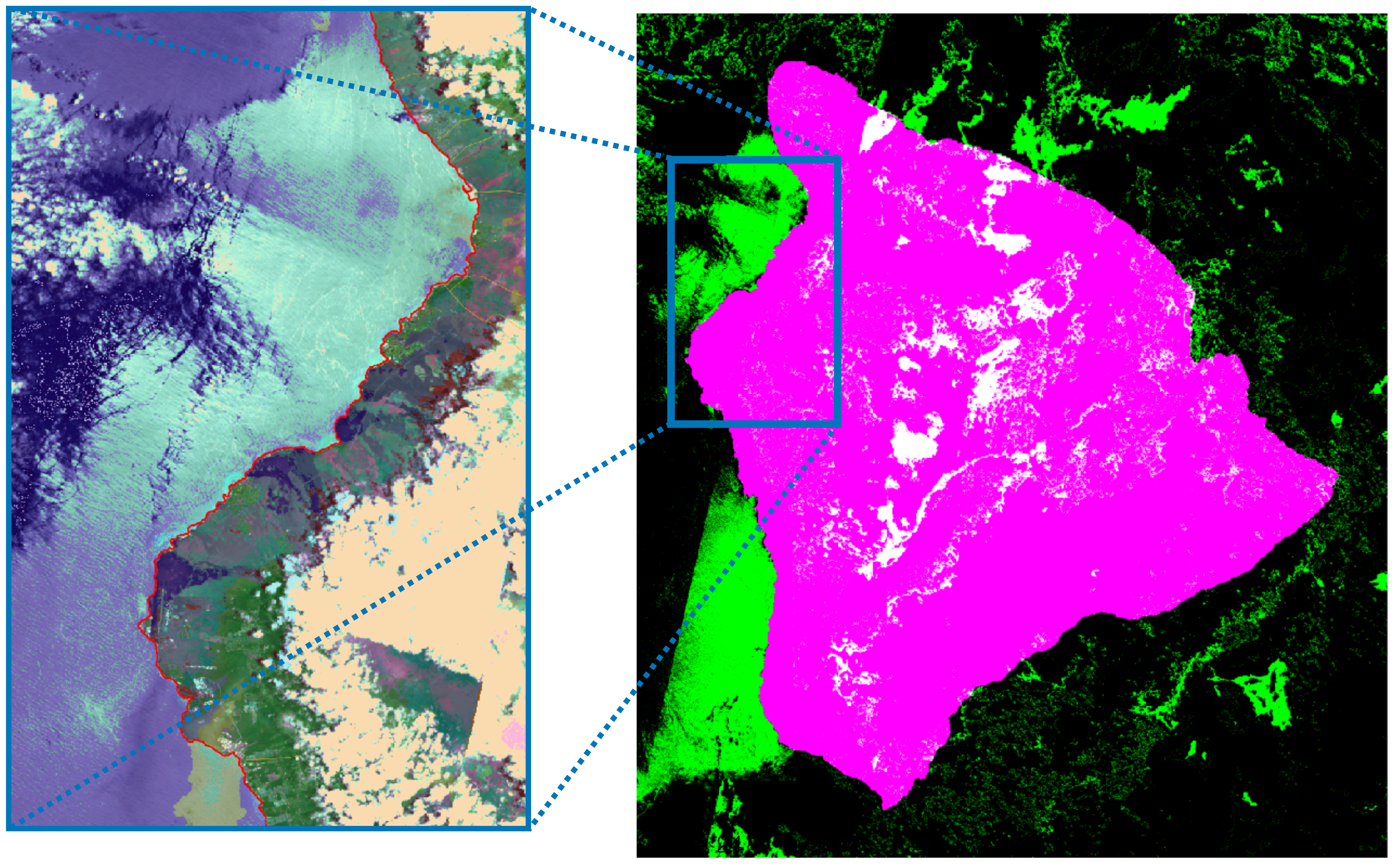





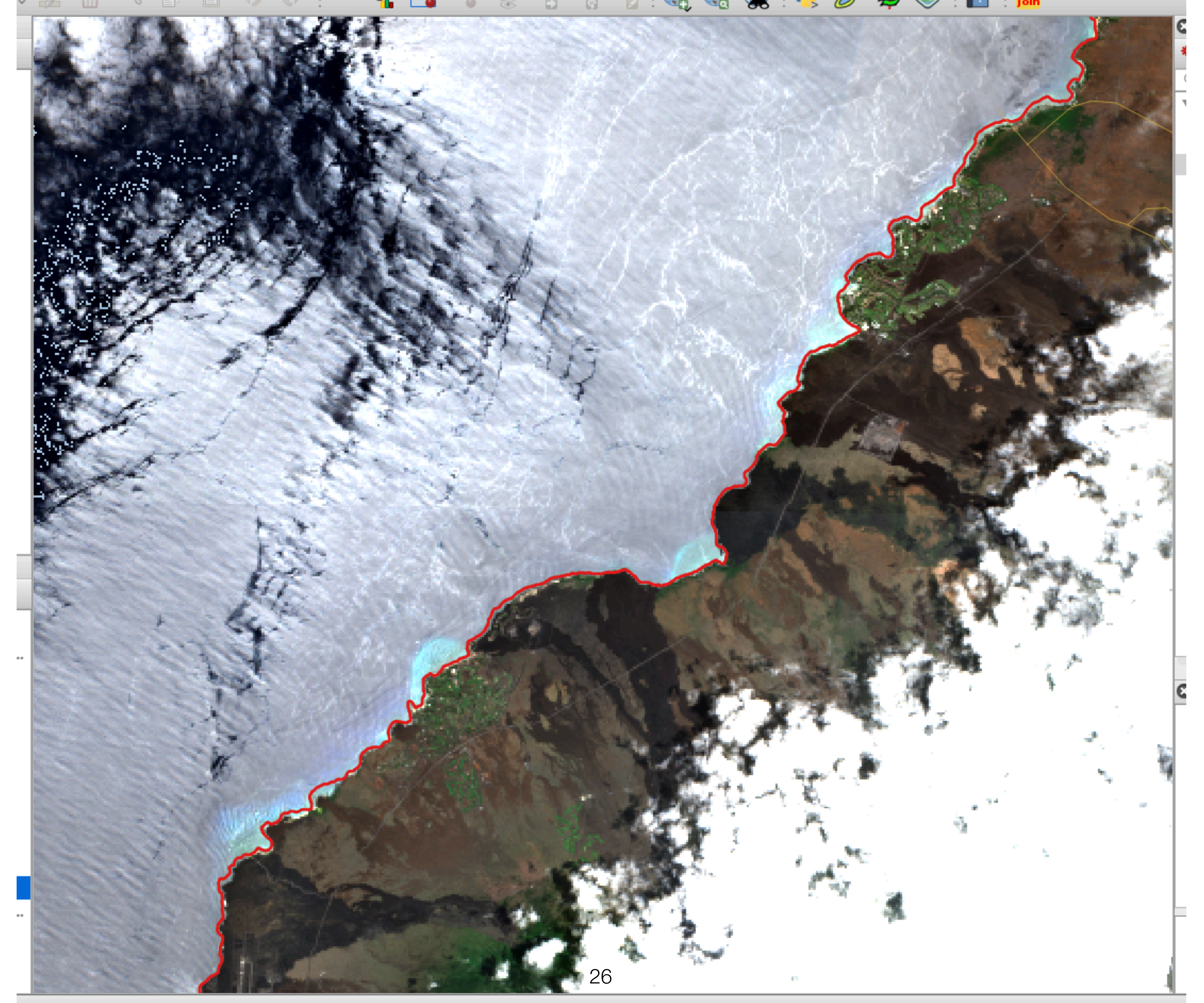




\section{Review}

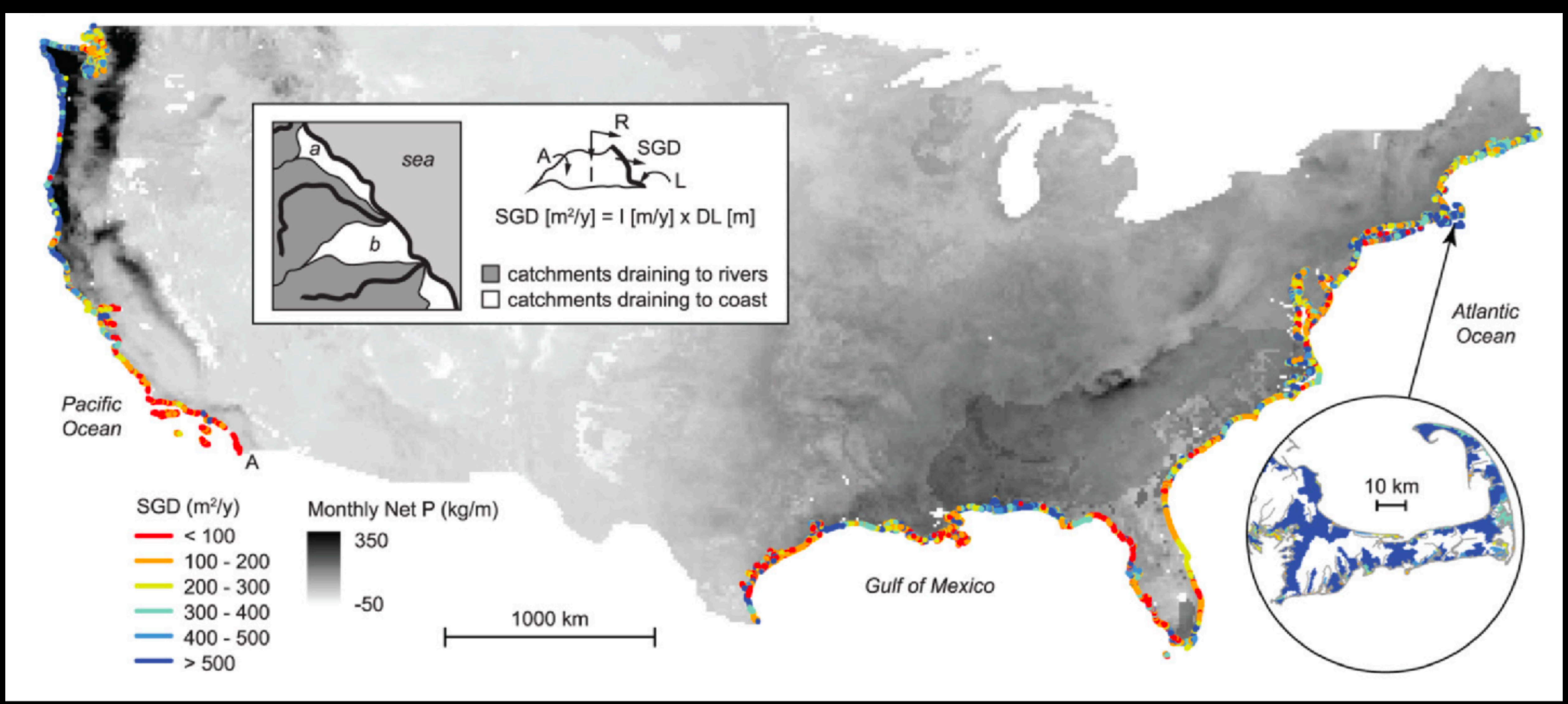

Sawyer et al., 2016 


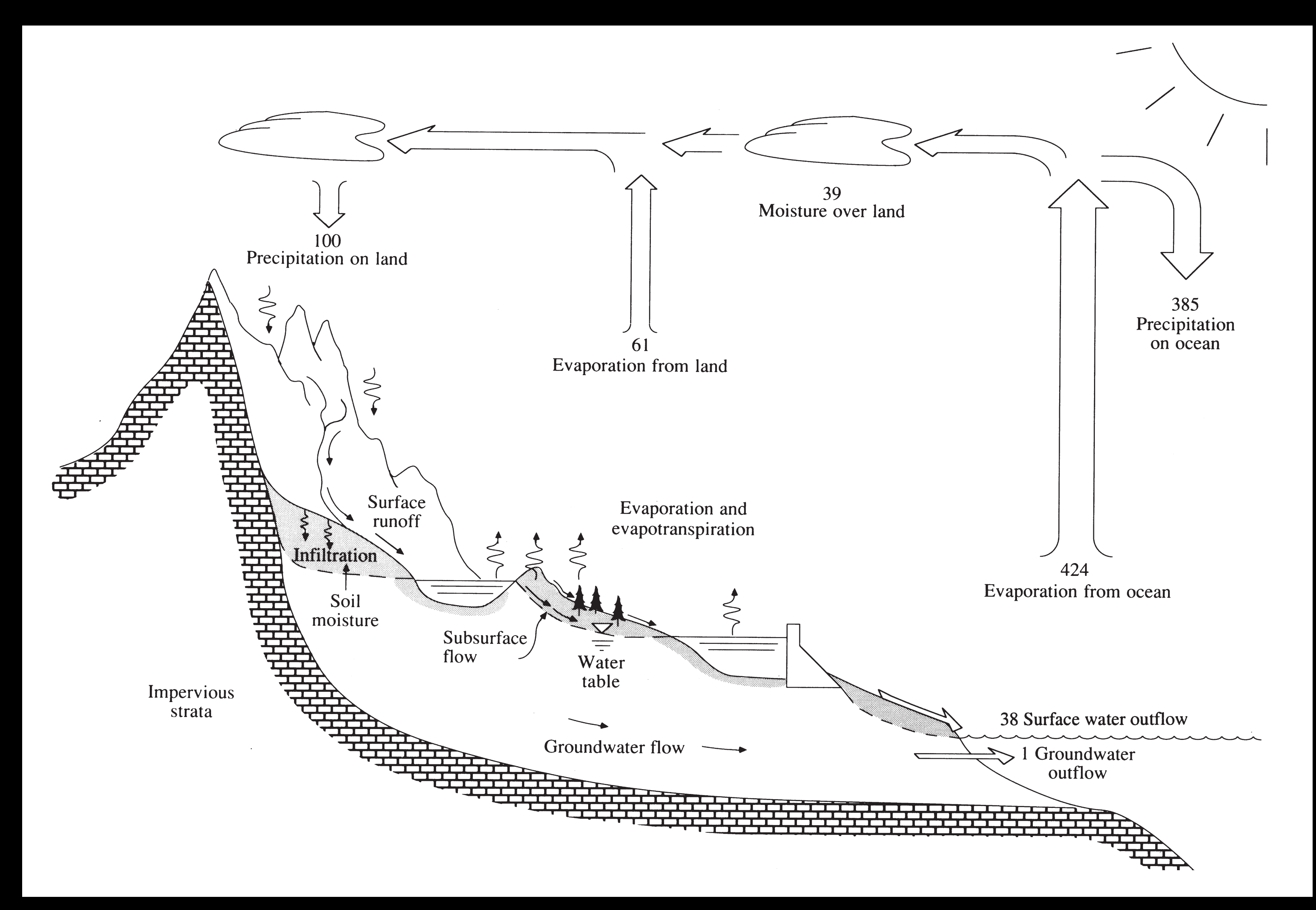

Chow et al., 1988 


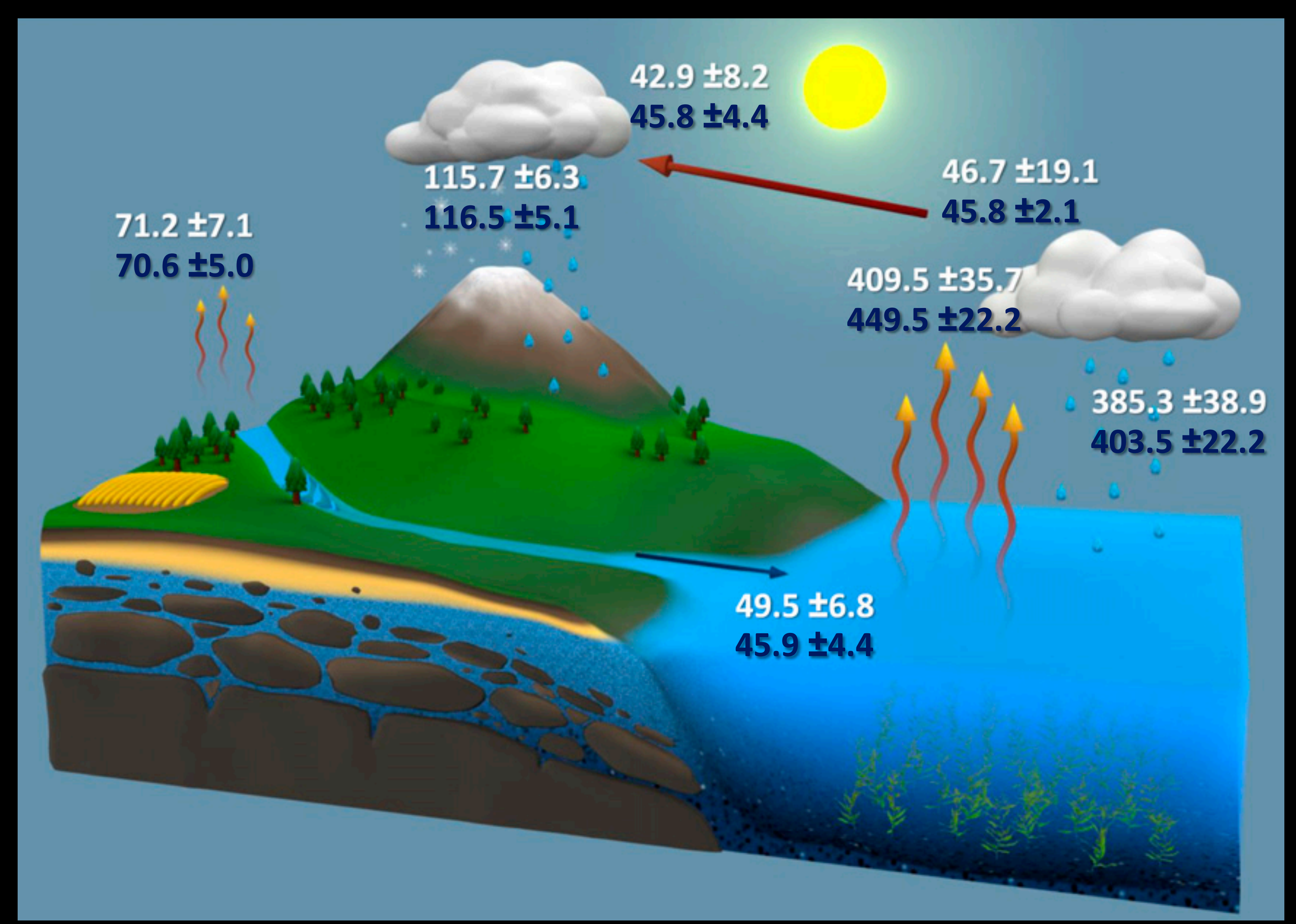

Rodell et al., 2015 


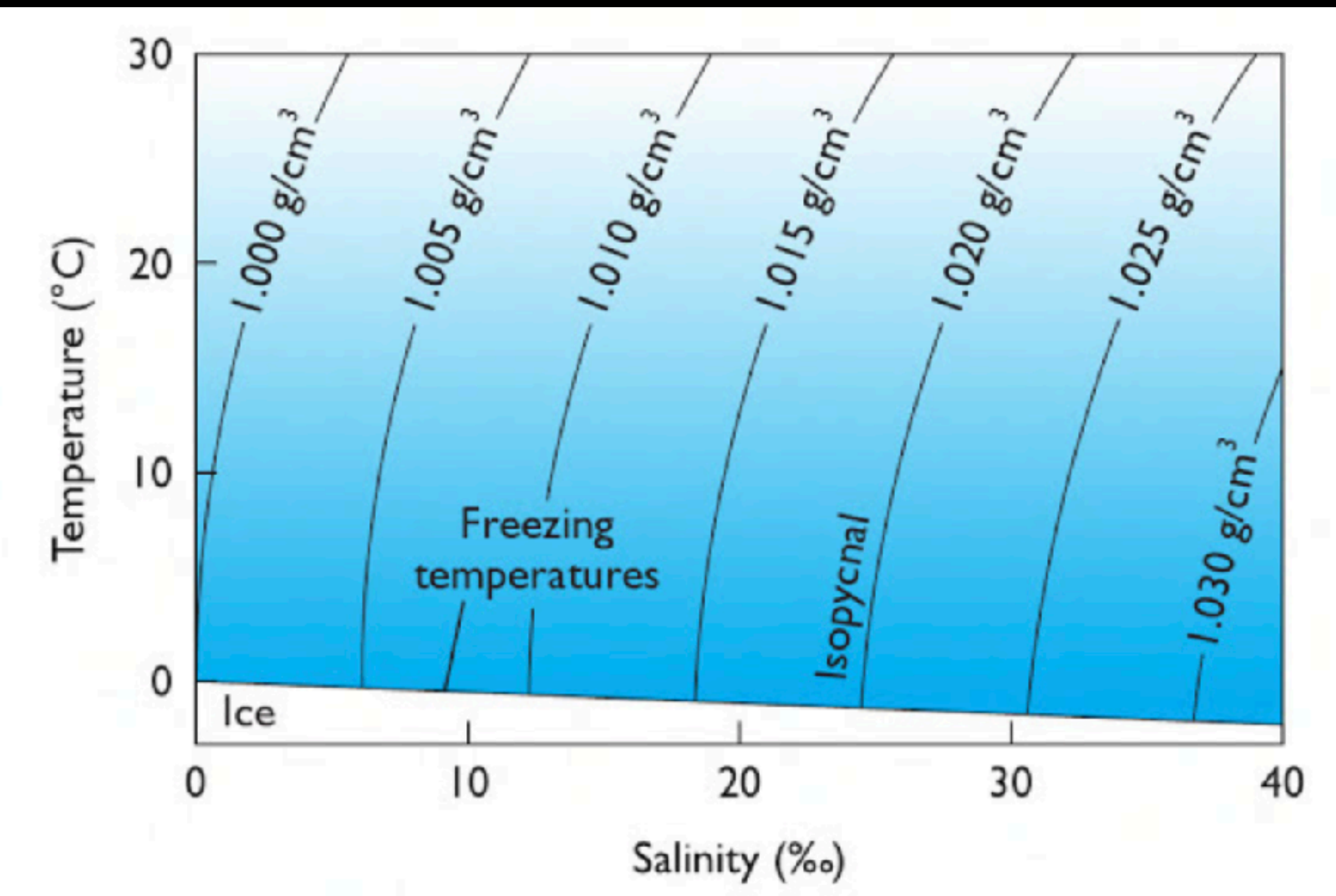

(a) SEAWATER DENSITY

Pinet, 2011 

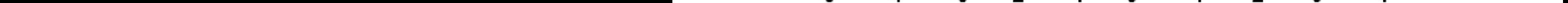

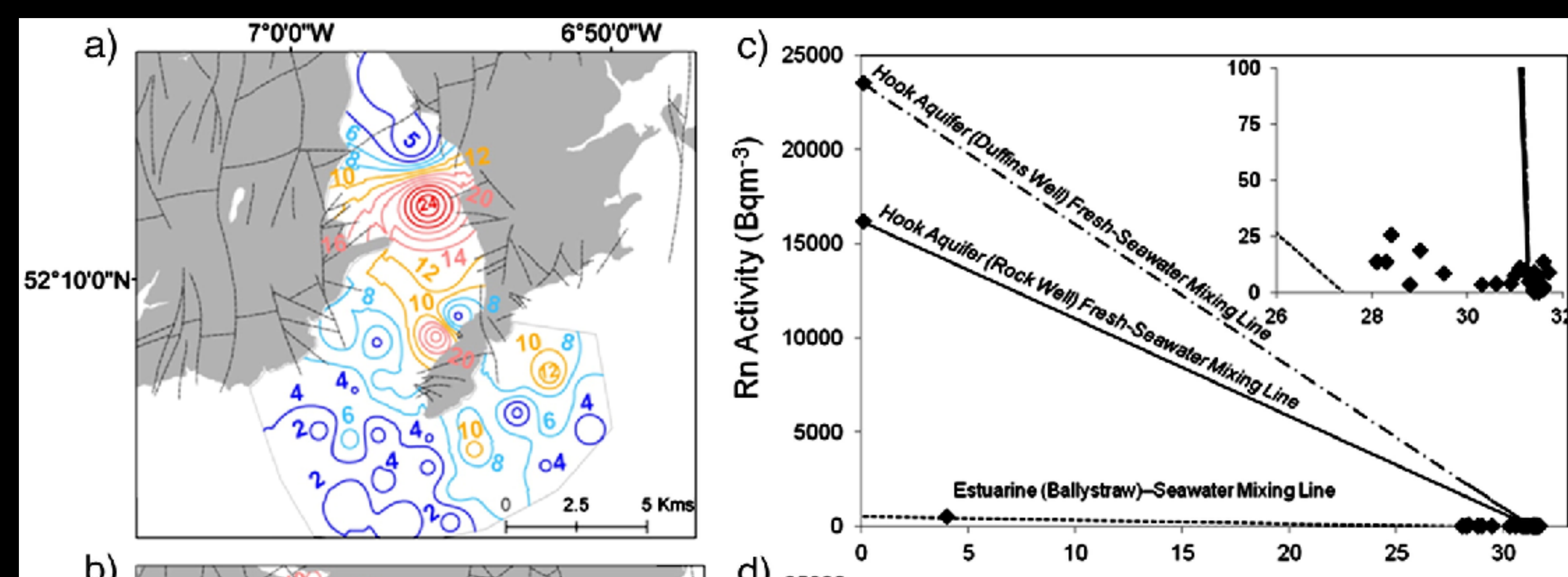

b)
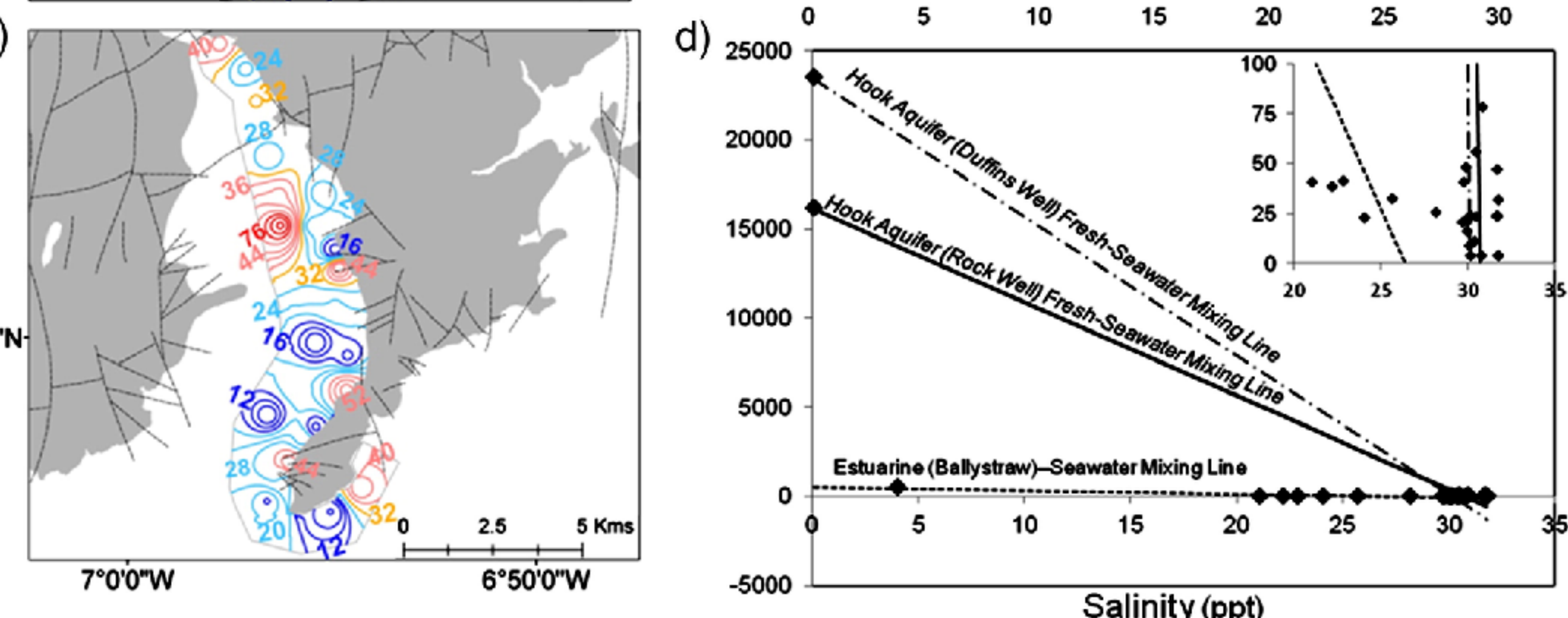


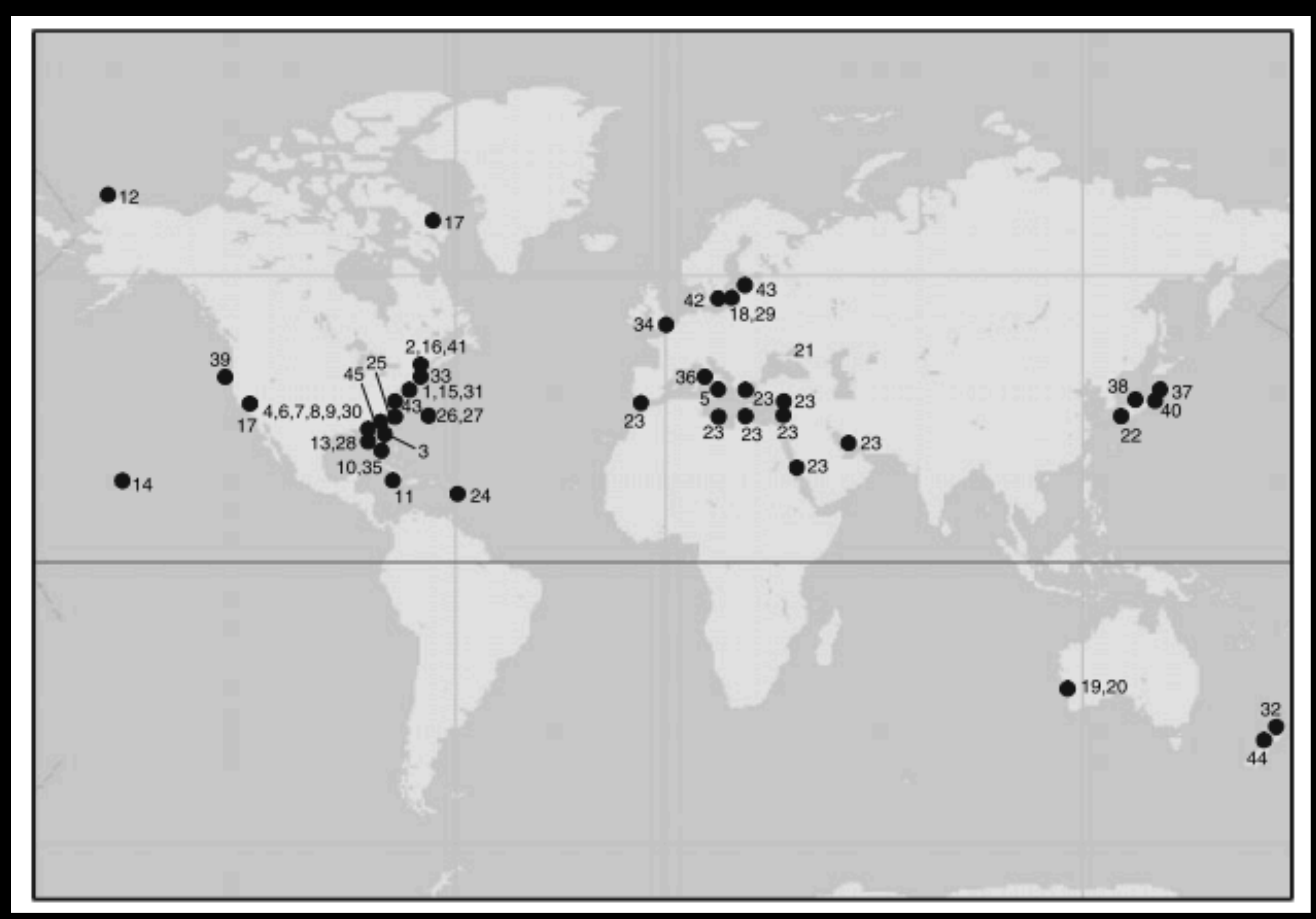

Taniguchi et al., 2002 


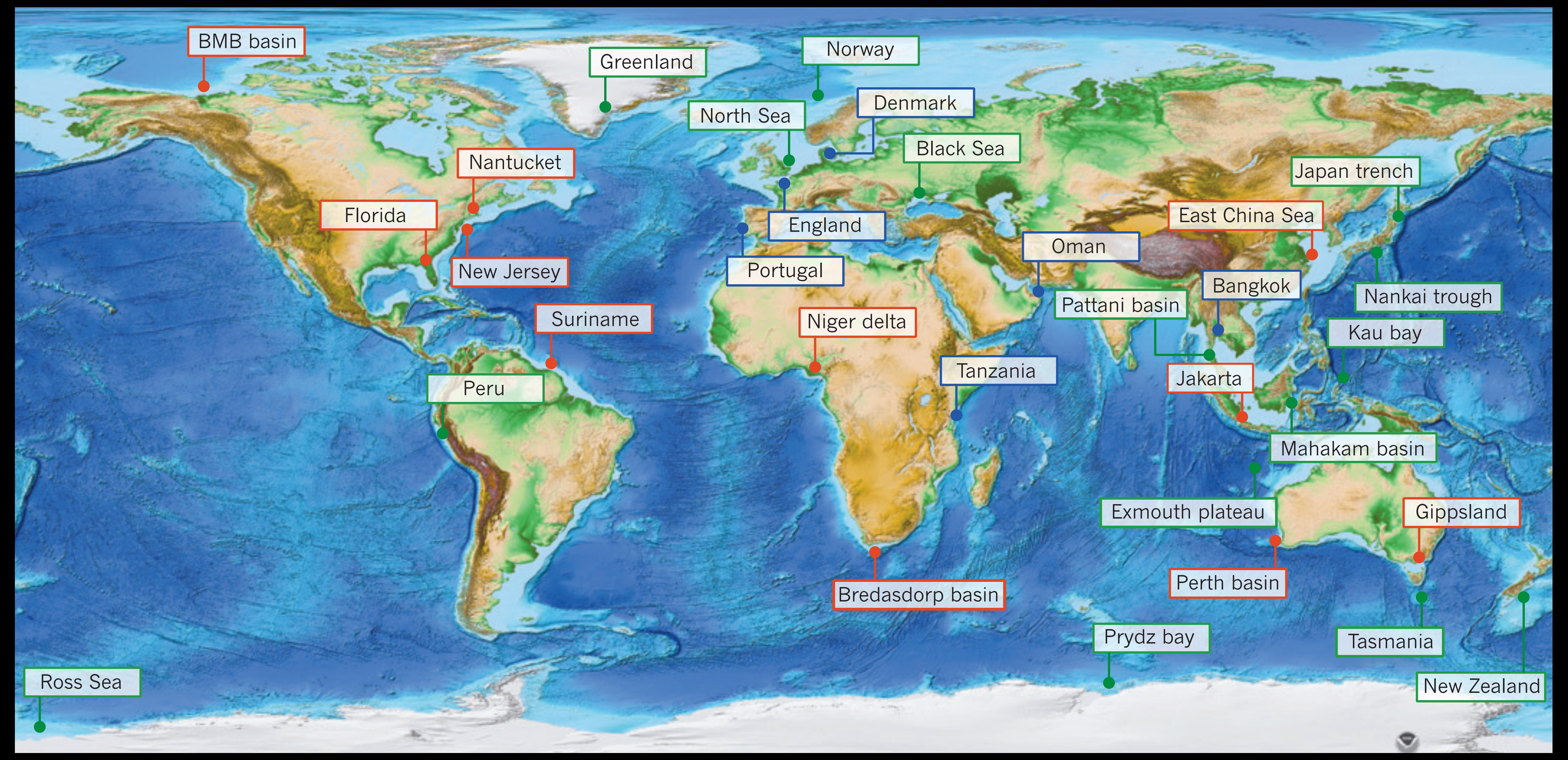

Post et al., 2013 


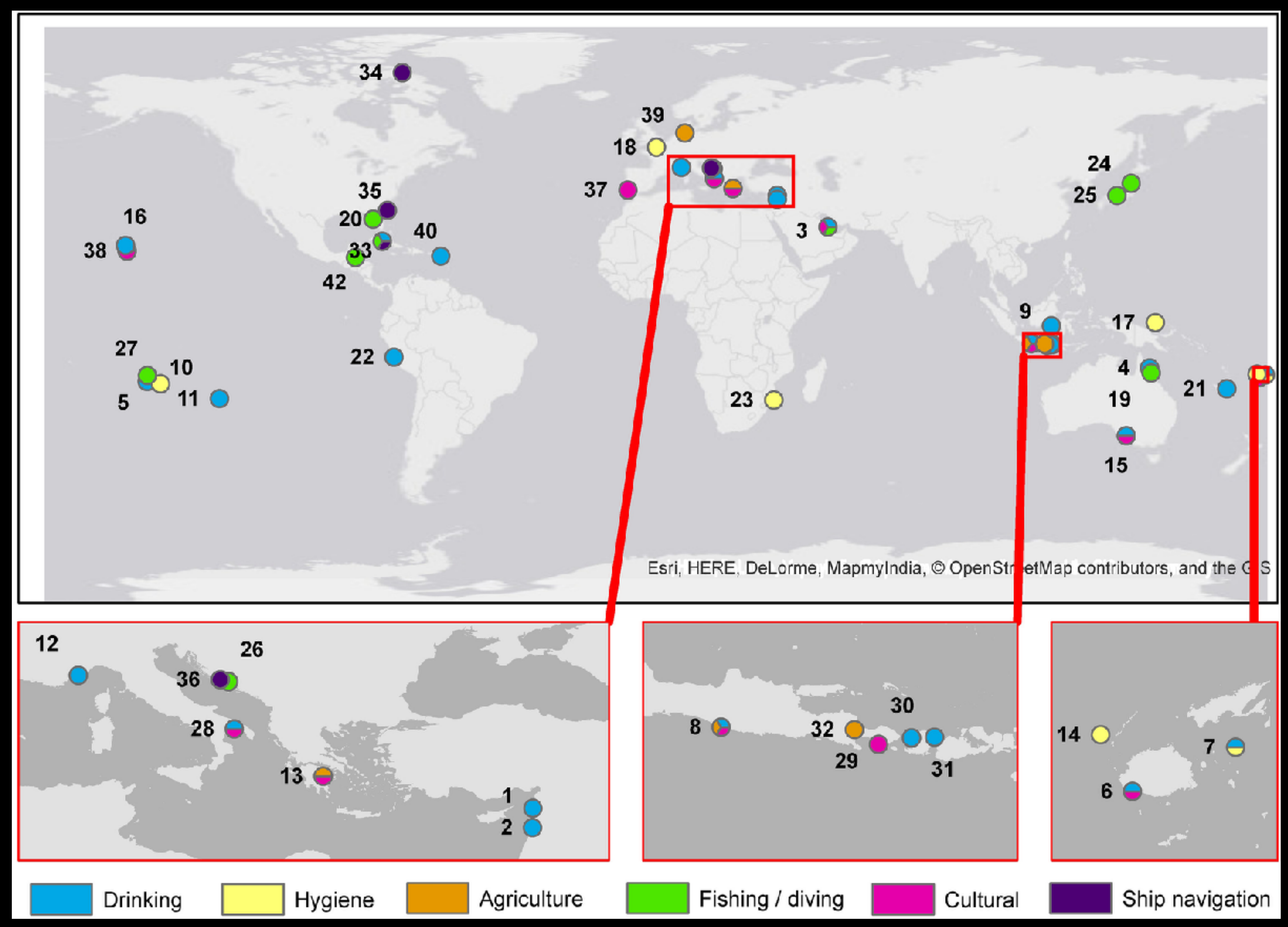

Moosdorf \& Oehler, 2017 


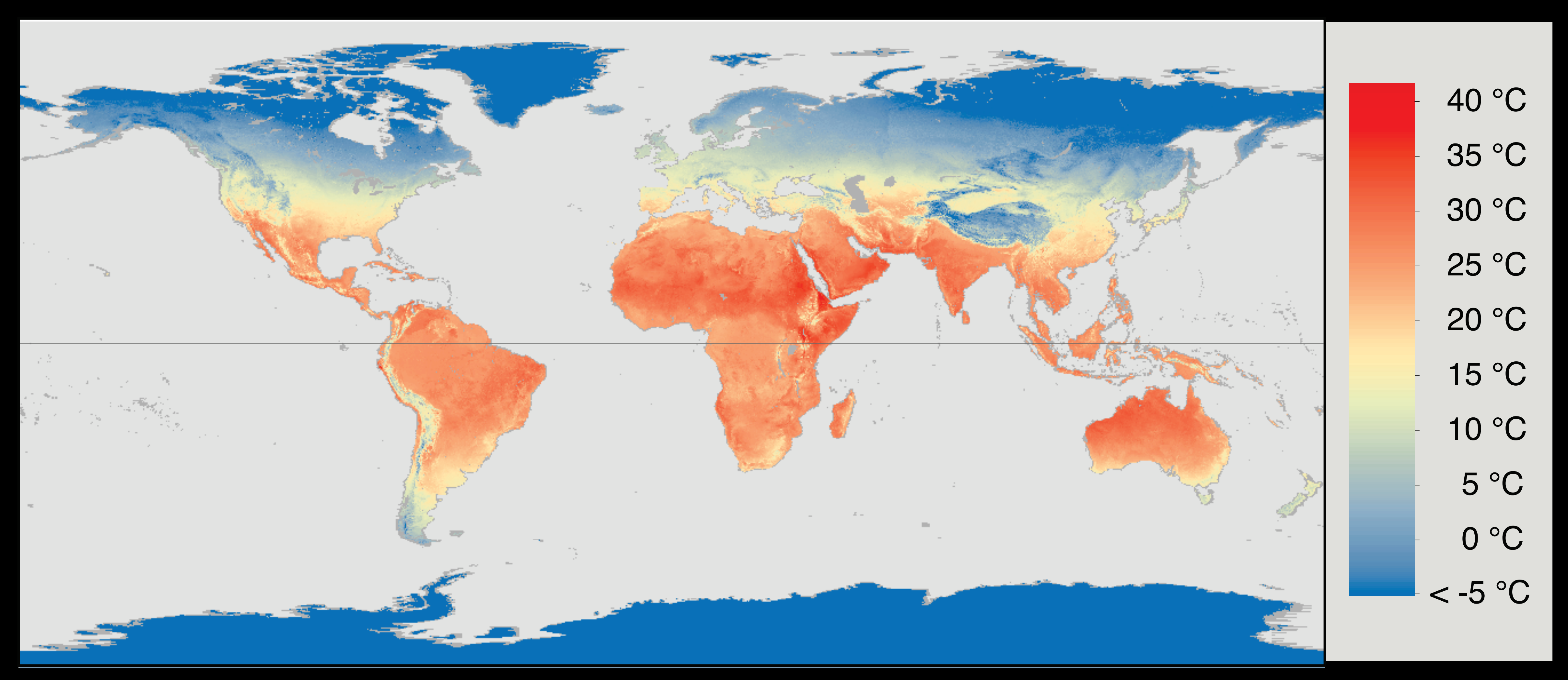

Benz et al., 2017 


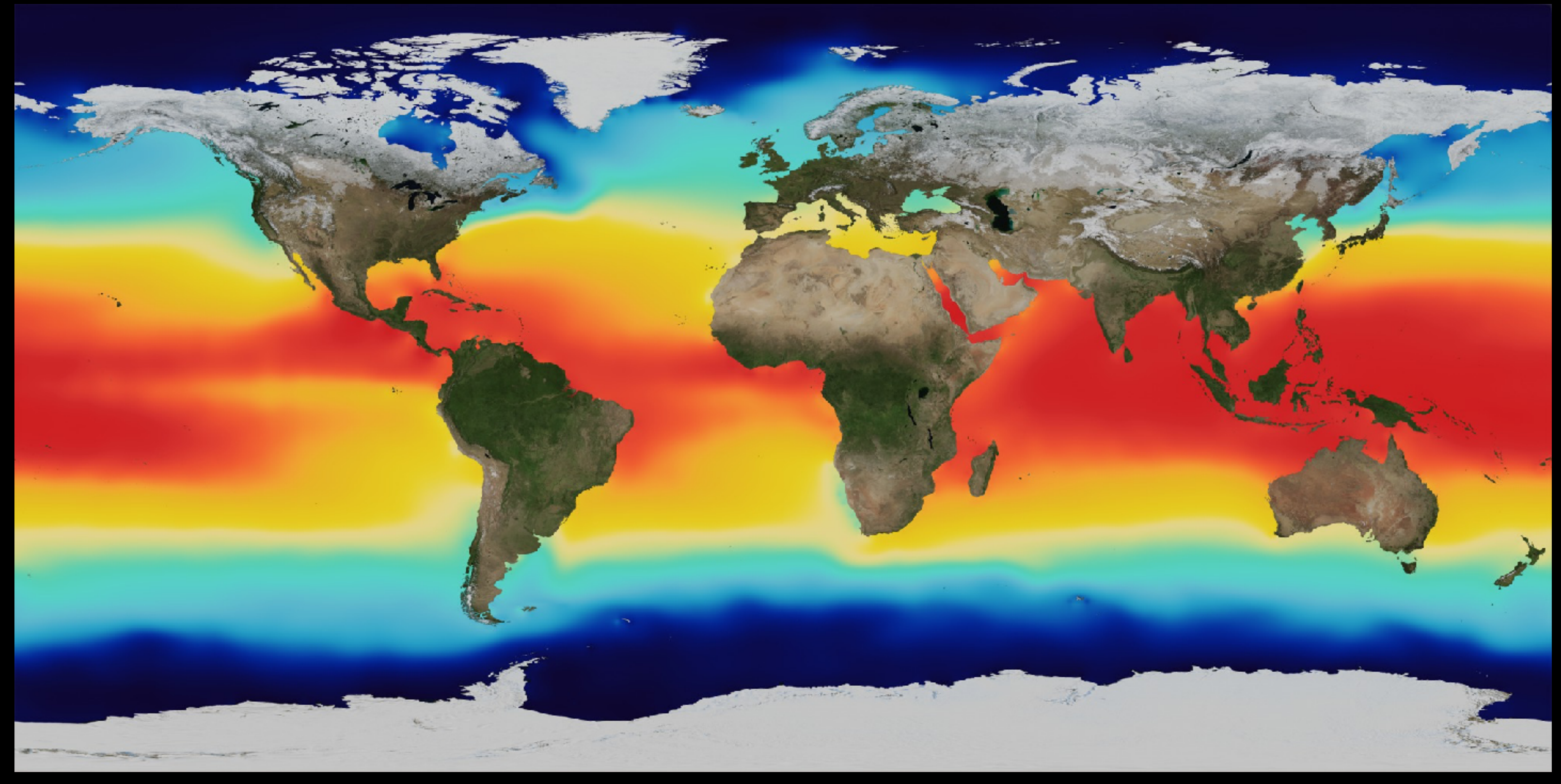

Sea Surface Temperature

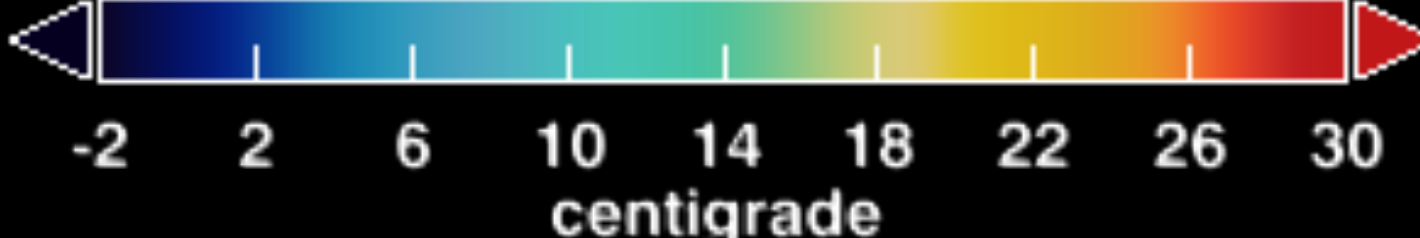

NASA/Goddard Space Flight Center 




Sea Surface Temp $\left({ }^{\circ} \mathrm{C}\right)$ 


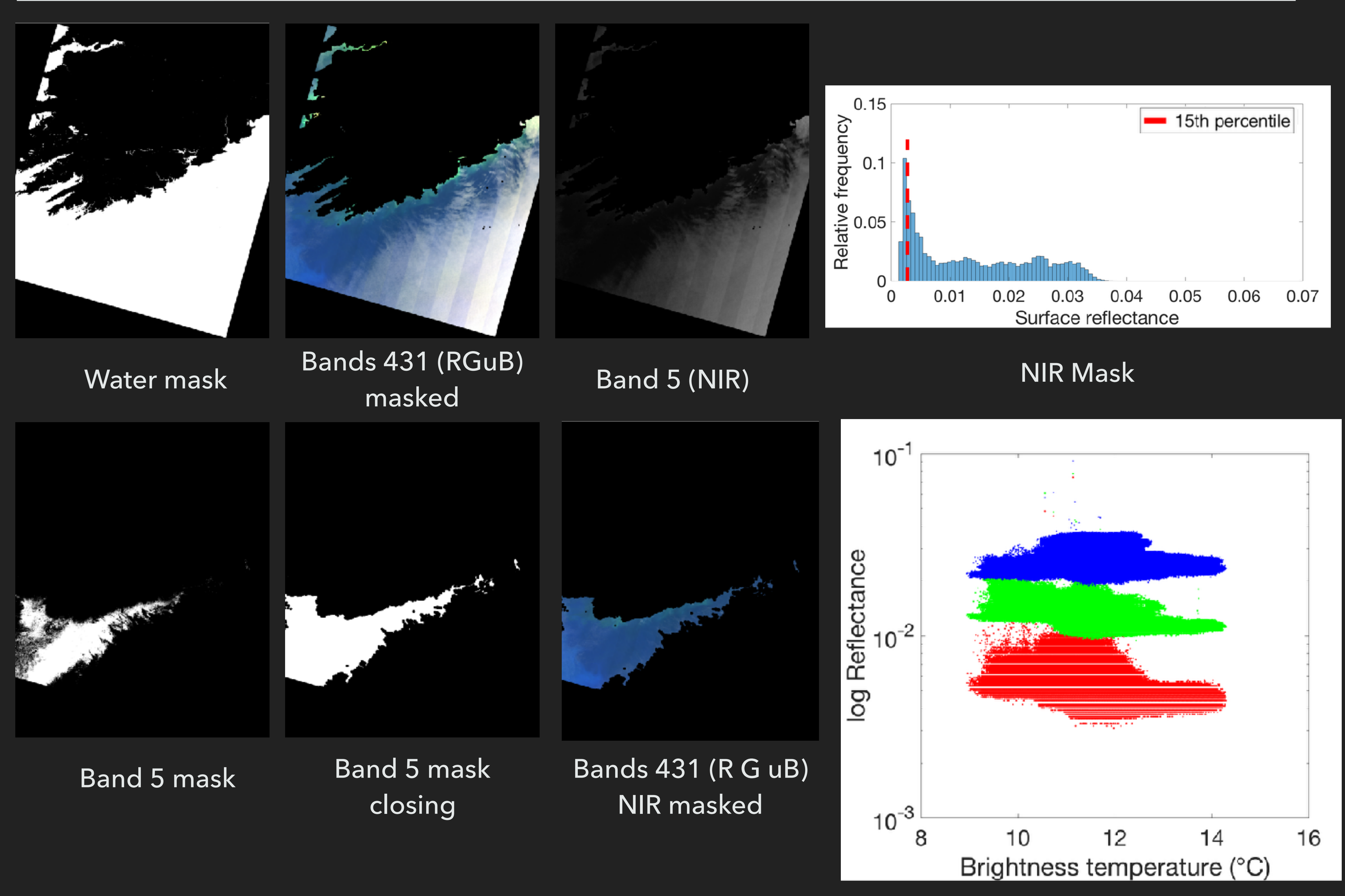



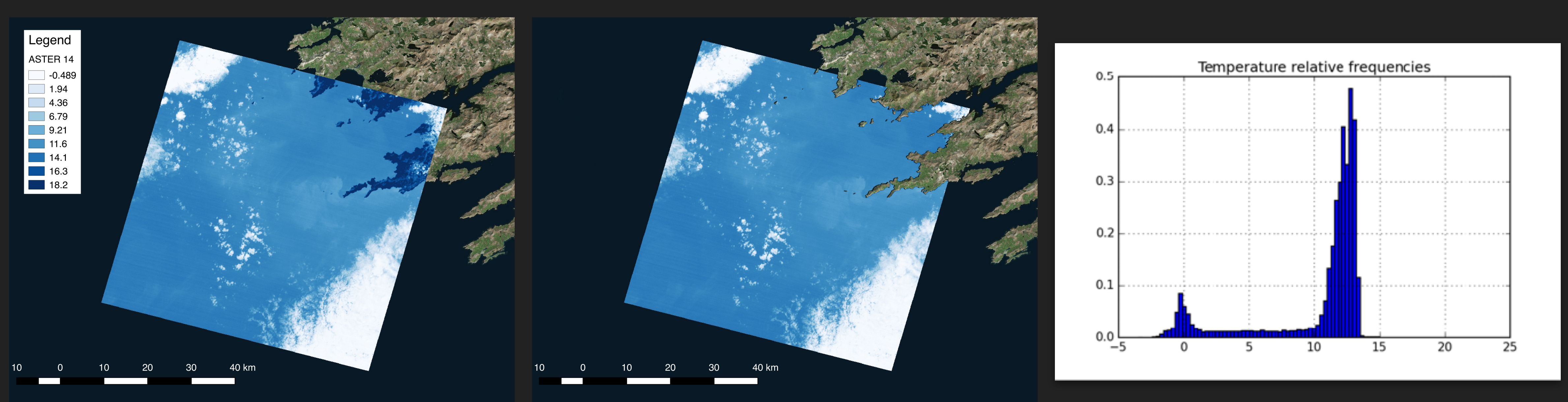

ASTER L1T Band 14 (10.95 - $11.65 \mu \mathrm{m})$ to ${ }^{\circ} \mathrm{C}$

Temperature histogram
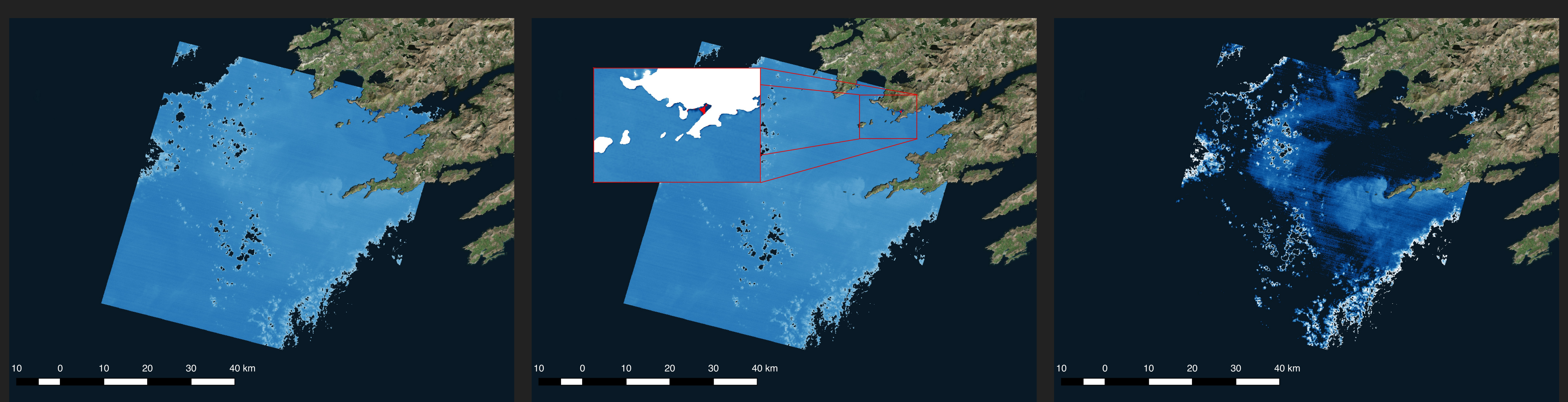

Mask clouds $\mathrm{T}>\overline{\mathrm{T}}-\sigma_{\mathrm{T}}$ 

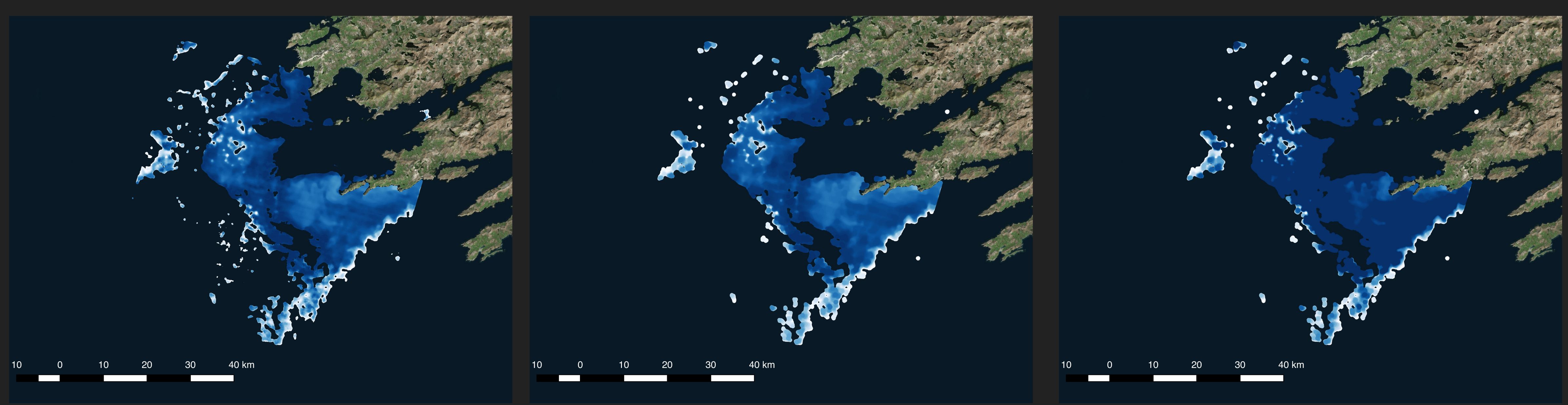

Median filter

Morphological opening


Histogram stretch 


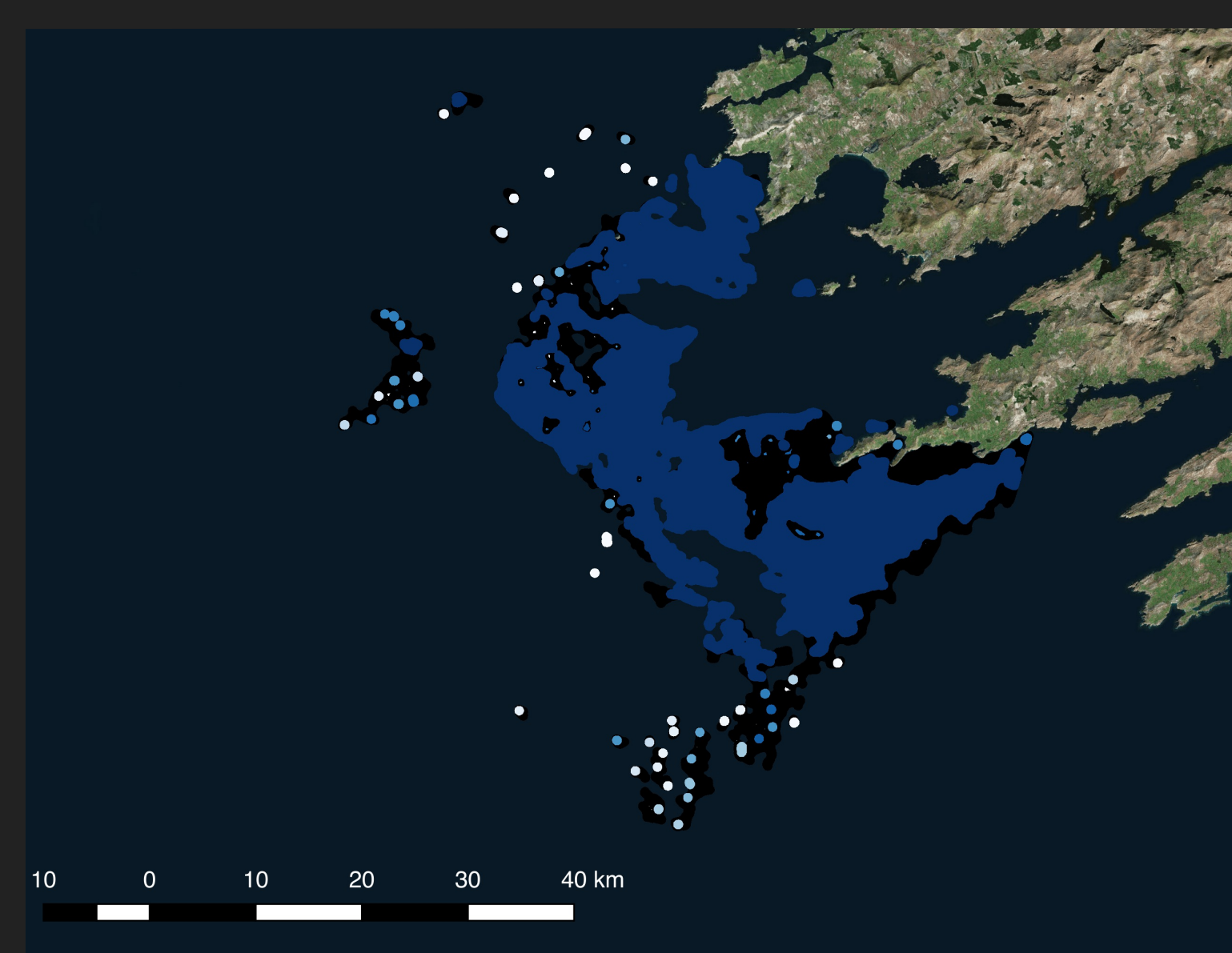

NOT(Local maxima OR Local minima)

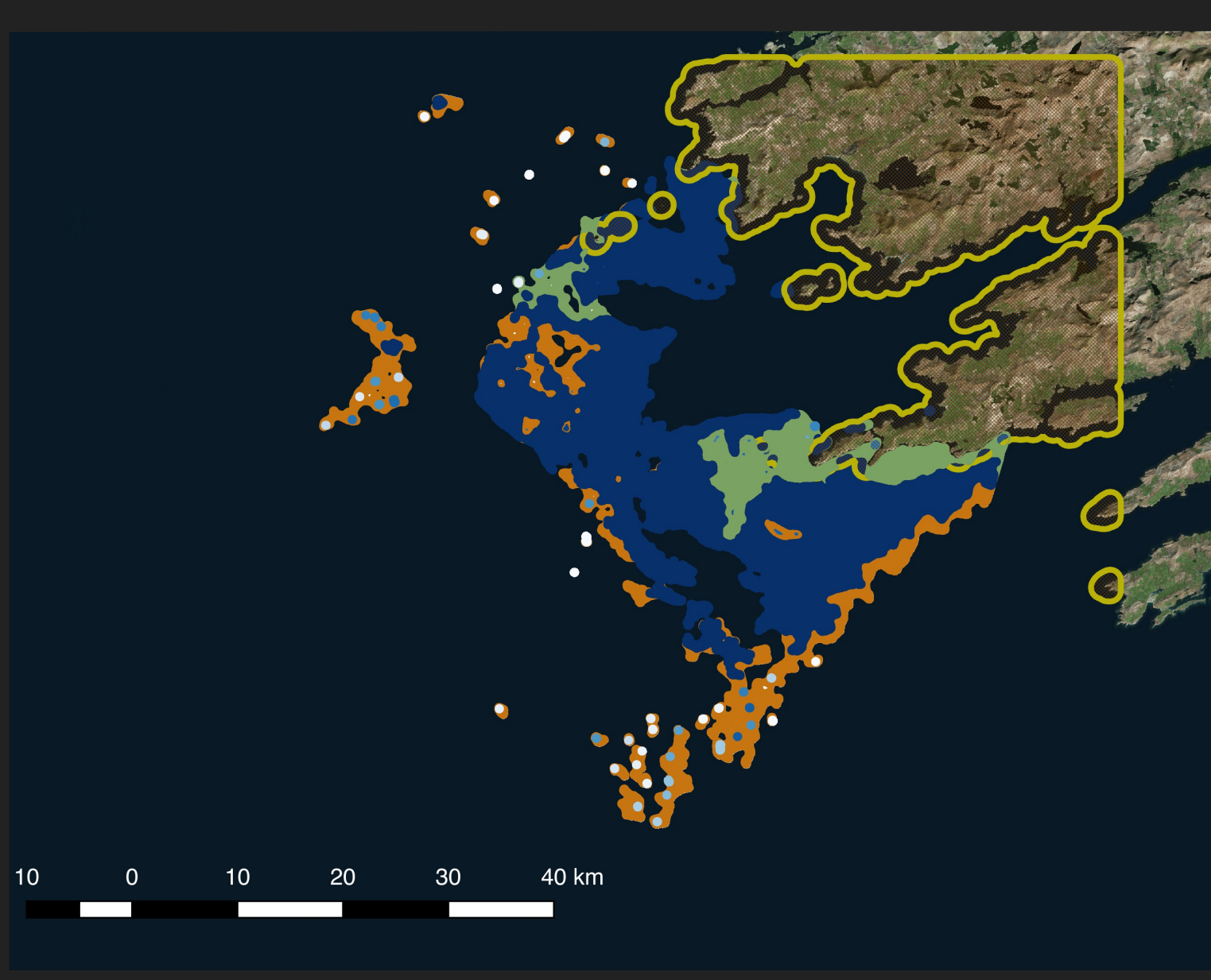

Select close to coast

$1 \mathrm{~km}$ buffer

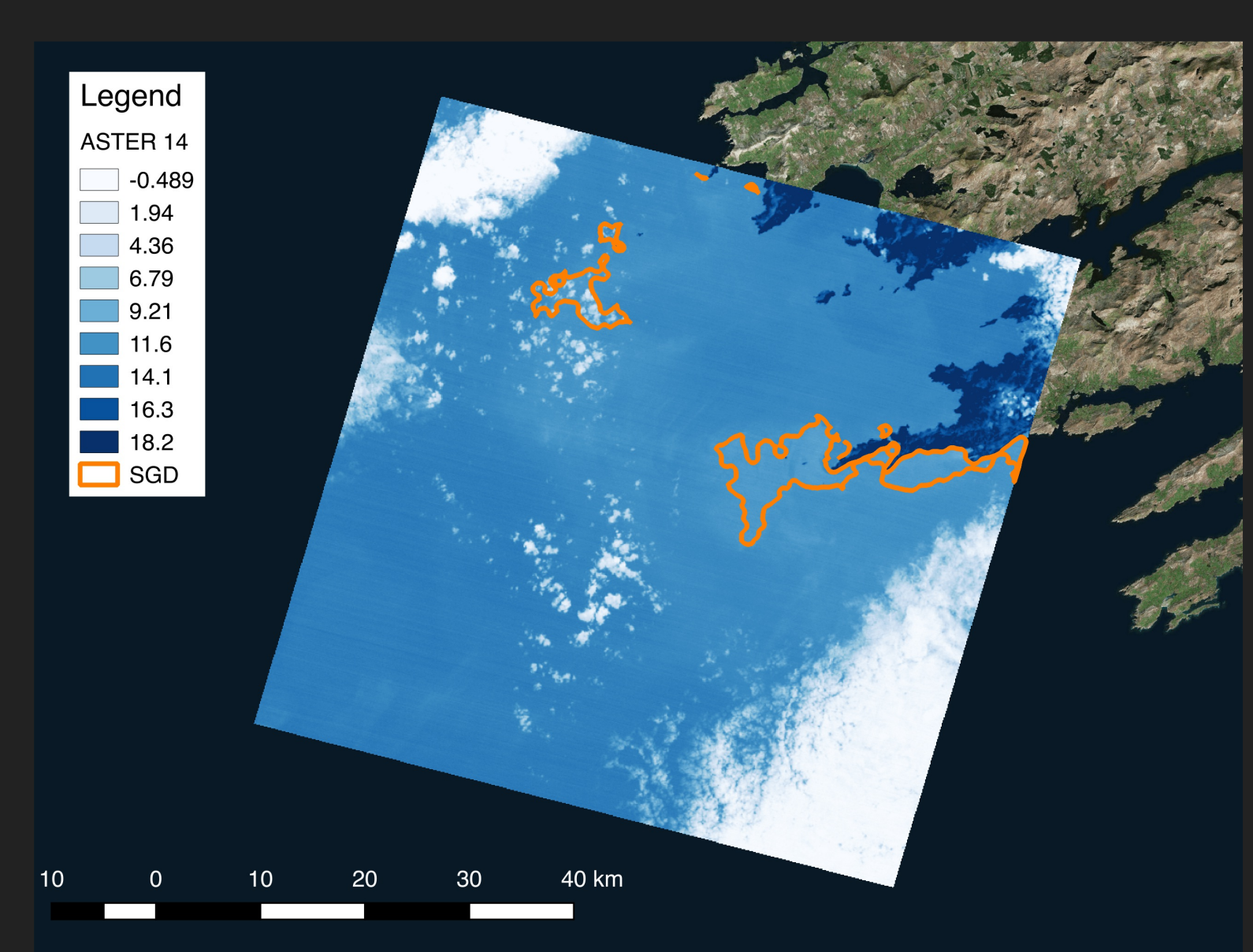

SGD plumes

automatically detected

\section{PROS}

CONS

- Automatic method $\quad$ May not work everywhere (untested)

- Pinpoint locations $\quad$ Assumptions may need fine tuning 